\title{
Pricing the Strategic Value of Poison Put Bonds
}

\author{
Alexander David * \\ Capital Markets Section \\ Board of Governors of the Federal Reserve System
}

November 1997

\footnotetext{
${ }^{*}$ Mailing Address: Mail Stop \#90, Federal Reserve Board, 20th \& Constitution Ave. NW, Washington D.C. 20551. Phone: (202) 452-2333. Fax: (202) 452-5296. E. Mail (Internet): adavid@frb.gov. The paper represents the views of the author and should not be interpreted as reflecting the views of the Board of Governors of the Federal Reserve System or other members of its staff. I am grateful to David Bowman, Mark Carey, Jennifer Carpenter, Greg Duffee, Joe Ostroy, Mitch Post, Gary TeSelle, Haluk Unal, and Chungsheng Zhou for helpful conversations and their advice on the issue, to Mike Pizzi for excellent research assistance, and to Mark Fisher for several Mathematica tips. I also thank Martin E. Welch III, Senior Vice President and Chief Financial Officer at Kmart for providing some important information about their deal. An early version of the paper was presented at the Seventh Annual Derivatives Securities Conference at Kingston, Ontario in May 1997, and at the Western Finance Association Meetings at San Diego, California, in June 1997.
} 


\begin{abstract}
The role of putable bonds as a defense against takeovers and as protection for investors against market and event risk has been appreciated in the literature, but the threatening power of put bondholders the ability to induce a financial crisis - has largely been ignored. In times of low liquidity for a firm, put bondholders can threaten to either force the company into a reorganization or to raise its borrowing costs. This threatening power implies that there is a difference between the intrinsic and strategic value of the option. Using recent results in bargaining theory, I solve for the strategic values of these options at the time of the triggering of the put. The theory is applicable both to cases where the bonds are held closely by a few institutional investors or the bonds are widely held by small market participants. It will be seen that the strategic values of players will depend on the following 'state' variables at the time of the put: (1) The size of the each lender's holding of the company's debt, (2) The size of the 'effectively' liquid assets of the company relative to the amount of putable debt outstanding, (3) The costs of bankruptcy, and (4) The prices of all financial assets at the time the put options are triggered. Prior to the crisis all financial assets are priced in a continous-time framework when interest rates follow the Vasicek process and firm's debtholders are subject to a sharp price decline due to an LBO. The model is calibrated to one such recent crisis - that of Kmart Corp.
\end{abstract}

JEL Classification: G33, G12 


\section{Introduction}

Poison put bonds first became popular in the late 1980s after a series of leveraged buyout transactions (LBOs) had reduced the values of target company's debtholders. They have remained popular in the 1990s with a large value of such bonds issued even before a new wave of takeover activity began in 1994. Investors hungry for yield have increased their appetite for speculative grade bonds, but have demanded protection against large downside risks. We estimate that poison puts have accounted for about 12 percent of all bonds issued by U.S. nonfinancial companies in the 1990s. While the roles of poison puts as anti-takeover defenses and as providing investors protection against event-risk (see for example, Crabbe 1991, Cook and Easterwood 1994) the threatening power of poison put bondholders - the ability to induce a financial crisis - has largely been ignored. In times of low liquidity for the firm, put bondholders can threaten to either force the company into a reorganization or raise its borrowing costs. This gives their bonds a strategic value in addition to the intrinsic value of the options. One such financial crisis is described next.

In December 1995, following several quarters of weak sales, Kmart Corp. came on the brink of a bankruptcy filing: Their problems stemmed from the possible exercise of $\$ 550$ million of poison put bonds outstanding, which allowed holders to sell back, or 'put' the notes back to the retailer, if the rating on the company's senior debt - as determined by either Standard and Poor's or Moody's - fell below investment grade. The putable debt was held by two sets of institutional lenders - banks and insurance companies and was not publicly traded. Despite having more than $\$ 1$ billion in cash and other marketable securities, Kmart was prohibited by covenants in its bank debt from accelerating payment on more than $\$ 100$ million of the putable debt. Exercise of the options, therefore, would force Kmart it into a bankruptcy filing. In December, the retailer's debt was rated two notches above junk status at 'BBB' by Standard and Poor's and 'Baa2' by Moody's. Kmart reached a settlement with the lenders, offering insurance companies that held the putable bonds a lump sum to surrender their options. While the settlement amount is unknown, it was rumored in certain press reports that a total of $\$ 98$ million was paid to putable bondholders and that an insurance company was offered five times as much per dollar as banks holding similar bonds. ${ }^{1}$ The settlement was accepted by bondholders and Kmart's shares soared 27 percent following the retailer's agreement with holders.

Several market imperfections inherent in the options transaction imply that there is difference between the intrinsic and the strategic value of the option. The former is the present discounted value under an equivalent martingale measure. The latter results due to bondholders having some threatening power on the firm in a time of financial crisis. The strategic values paid in informal bargaining situations to creditors are determined through bargaining between the firm and the putable bondholders. Some of the market imperfections are: (i) the bonds are not publicly traded, (ii) one large bondholder held a fifth of the face value outstanding and several (15-20) smaller bondholders held the remainder, (iii) the firm is liquidity

\footnotetext{
${ }^{1}$ Bloomberg Financial Service, November 15th 1995. "Kmart Seen Offering Lump Payment to Remove Put Option."
} 
constrained and is prohibited by covenants to refinance the put debt costlessly and (iv) there are direct (and perhaps indirect) costs of bankruptcy.

The value of different bondholders options in such situations depends on their bargaining positions. Using recent results in N-person multilateral bargaining theory (Hart and Mas-Colell (1996)), I solve for the strategic values of these options. The solution of the non-cooperative game coincides with a cooperative game theory concept - the Shapley Value - and assigns a strategic value to each player equal to his expected marginal value. The expectation is with respect to the uniform measure over all coalitions that can potentially be formed. In the model described, the 'probability' of each bondholder being in a threatening coalition is shown to be a function of the effective liquidity-to-putable debt ratio of the firm. It is shown that the strategic values of different sized bondholders are different and differ significantly from the intrinsic values of these options. Even when the number of bondholders increases to infinity, the two values will not coincide for an effective liquidity-to-putable debt ratio less than one. It will be seen that the strategic values of players will depend on the following variables at the time of negotiations: (1) The size of the each lender's holding of the company's debt, (2) The size of the 'effectively' liquid assets of the company relative to the amount of putable debt outstanding, (3) The expected costs of bankruptcy, and (4) The value of nonputable bonds and equity.

Prior to the crisis, we formulate the prices of all financial assets in a frictionless framework (no liquidity problems). It is assumed that interest rates follow the Vasicek (1977) process and that the firm files for bankruptcy (defaults) when the value of its assets hits a lower bound. The default boundary depends on the face value of all debts outstanding and exogenously given recovery rates of each class of liabilities. The firm is subject to an LBO, which raises the amount of its junior debt and hence leads to an increase in the default boundary. Therefore, even though the asset process is continuous, the prices of bonds are subject to sharp decreases in the event of an LBO. We will note that such a model is consistent with the observed high spreads for bonds with short maturities. We then calculate rating boundaries for the asset value at which the poison puts can be exercised; at these boundaries the probabilities of default match the default probabilities for the put-triggering rating (for example, Ba in the case of Kmart) for bonds rated by Moody's. The values of the poison puts prior to the crisis, are the solution of a partial differential equation with boundary conditions (at the rating boundaries) determined by the bargaining solution as discussed above.

The violation of absolute priority in debt contracts (see for example Franks and Torous 1989) is an indicator of strategic behavior among various creditors of the firm in and before bankruptcy. Several recent papers have modeled the strategic behavior and its impact on bond valuation. In Anderson and Sundaresan (1996) and in Mella-Berral and Perraudin (1997) the firm is able to make take-it-or-leave-it offers to bondholders at the time coupons and principal is due. They show that if the firm is unconcerned about reputational concerns in their ability to issue future debt, then its offers a strategic debt service, which in many situations is smaller than the promised sums. We shall abstract from such behavior by borrowers by 
assuming that firms must offer bonds periodically and do not want to harm their reputations. In addition, we model multilateral bargaining with alternating offers, a framework in which the first-mover advantage is small when the players are patient (or the costs of delay are small). Aivazian and Callen (1983) proposed the Shapley Value as the solution to the bargaining problem between shareholders and bondholders; Bergman and Callen (1991) used the alternating offers framework of Rubinstein (1982) as the solution. Both papers assume that bondholders bargain jointly as a group with shareholders in a 2-person game. Because one on our goals is to study the relative strategic value of large and small creditors we formulate an N-person game. The bargaining solution coincides with the Shapley value, but we point to an explicit non-cooperative game with alternating offers that has the Shapley Value as its unique solution. In addition, we price strategic value of bondholders in an environment with stochastic interest rates. Dunn and Spatt (1984) report and price strategic value in the sinking fund bond market; hoarders attempt to corner the market for the firm's bonds, so that repurchases from the open market are unavailable. They then demand payments greater than face value from the firm.

The plan for the paper is as follows: General Characteristics of the Put Bond Market are in Section 2. In Section 3, nonputable bonds are priced in a frictionless framework in which the target firm's debt is subject to a sharp price decline due to an LBO. In Section 4, the capital structure of the firm with poison puts is described, and the frictionless structure is adjusted to incorporate the timing and rules of the bargaining game that arises when covenants in poison puts are violated. In Section 5, intrinsic and strategic values for poison put options are defined. Strategic values are solved for when the putable debt is divided equally among an arbitrary number of bondholders in Section 6, and when one large bondholder holds a significant amount of the debt in Section 7. The model is calibrated to Kmart's situation in Section 8. The pricing of two different variants of poison puts at the time of issuance is in Section 9. The conclusion and some implications are in Section 10.

\section{Acquisition Activity and the Poison Put Bond Market}

After a relatively quiet period in the early 1990s, a new wave of merger activity in the nonfinancial sector began in 1994, and has been grown in strength since then. Bolstered by the purchase of small companies, the number of deals completed has increased steadily over the past 12 years. However, the aggregate value of targets acquired displays two distinct waves (Figure 2, top panels); the aggregate value of targets acquired was about $\$ 130$ billion per year in 1984-1989, sank to about $\$ 50$ billion in $1990-1993$, and has been about $\$ 220$ billion from 1994-1997.

There are some major differences in the acquisitions consummated in the two waves. In the wave of the 1980s cash was the dominant mode of financing the purchase targets, mostly financed by a large increase in acquirers' debts. In the current wave, more than half the consideration offered to targets' shareholders has been in the stock of the acquirer. This feature is displayed in the top right panel of Figure 2: the 
dark portion in the top right panel represents the equity of the target company retired as a result of the acquisition; the remainder of the deal value was paid in the stock of the acquirer. Deals in which the stock of public companies was purchased by leveraged buyout firms and private investor groups — classified as LBOs — were an important phenomenon in the 1980s, accounting for 30 percent of the deal value (Figure 2 middle panels). In contrast, their role in the current wave has been almost negligible. The academic literature has identified two important motivations for leveraged buyouts and hostile acquisitions: reducing incentive and agency cost problems between management and shareholders, and improving the operating performance of the targets, often through extensive asset sales. The smaller share of such deals in the current merger wave is in line with the view that nonfinancial corporations have generally been operating more efficiently, and that shareholders gains in the bull market have been at or above expectations. Concomitantly, the percentage of deals classified as hostile has dropped sharply from almost 30 percent in the 1980s to less than 8 percent in the current wave and the percentage of intra-industry deals has risen substantially from about 41 percent to 66 percent. The larger percentage in the current wave reflects both the smaller role of financial buyers and the greater number of strategic combinations among firms in the same or related businesses.

Despite the large number of friendly stock mergers in the 1990s, almost $\$ 100$ billion of nonfinancial equity has been retired from cash deals each year since 1994. The debts of several of the firms involved in deals with significant equity retirements have been downgraded by the rating agencies. While the number of LBOs completed recently has been small, funds raised by non-venture private equity investors — which include specialist LBO firms - have continued to grow rapidly: such funds drew in about $\$ 50$ billion in 1995 and 1996, and increased that total by another $\$ 20$ billion in the first half of 1997 (Figure 2, bottom left panel). A more complete discussion of these funds can be obtained in Fenn, Liang and Prowse (1997). Press reports indicate that at least four large firms drew in funds in the $\$ 3-6$ billion range in the first half of 1997. Several practitioners have noted that buyout firms will likely make substantial purchases in the event of a significant market correction. The enhanced acquisition activity among nonfinancial firms with credit quality implications, and the impending threat of a leveraged buyout has prompted robust issuance of poison put bonds in the 1990s (Figure 2, bottom right panel). Cumulatively, about $\$ 141$ billion of poison put bonds have been issued since 1991, with the median issuer issuing a face value of about $\$ 250$ million. Data from the Flow of Funds at the Federal Reserve Board indicates that U.S. nonfinancial corporations have cumulatively issued about $\$ 1,100$ billion of bonds in the same period; therefore, poison puts have accounted for over 12 percent of all nonfinancial issuance in the 1990s. As seen in the figure, most of the volume has been from speculative grade issuers.

Poison put bonds were initially designed to make firms less attractive as takeover targets (by increasing the immediate financing needs of prospective acquirers) and thus provide an additional mechanism for strengthening managerial resistance to hostile bids. Their popularity increased rapidly in the late 1980's after leveraged buyouts lowered the credit quality of many firms and threatened the liquidity of corporate bond markets. In response to investors demand for protection against 'event-risk', these puts gave holders 
rights to sell their bonds back to the issuer at par in the event of a leveraged restructuring and subsequent downgrading. Initially, most puts were exercisable if there was the threat of a hostile takeover. Since most targets agreed to turn 'friendly' just prior to the acquisition but still experienced a decline in their credit quality, it became common to make the bonds exercisable upon any change in ownership or recapitalization and a 'large' downgrading of the debt by either Standard and Poor's or Moody's (see for example, Wrinkler 1988, Weberman 1988). Nash, Netter and Poulsen (1997) report characterisics of poison puts issued in 1989. Conditions (non-mutually exclusive) that could trigger the poison put included the following contigincies: the company merges with another company (about 67\%), an individual becomes a benefitial owner of more than a certain percent of stock ( $82 \%)$, a change in majority of the board of directors (42\%) or a sale of all or substantially all assets $(22 \%)$. In a third of the poison puts, the debt had to be downgraded in additon to one of the triggers mentioned. Crabbe (1991) estimated that the protection these bonds provided investors against 'event risk' in the late 1980's reduced yields by about 30 basis points in the secondary market. The number of contigencies covered increased in subsequent contracts, often leading to extended legal battles before an effective exercise of the puts. In the 1990s, poison put bonds evolved (such as that of Kmart Corp.) that were exercisable just on a rating change alone, thus protecting the bondholders from declines in credit quality irrespective of the cause.

\section{Pricing Non-Putable Bonds}

We shall solve bond prices for a firm with protected debt outstanding. The basic structure of the model is as in Black and Cox (1976), Longstaff and Schwartz (1996), and Briys and de Varenne (1997). ${ }^{2}$ In this section, the firm defaults only when the value of its assets hits an exogenously specified default boundary (discussed below). Later we will adjust the framework to price bonds when the company may be forced into a reorganization before its value hits the default boundary by the exercise of outstanding putable bonds.

\section{Assumption 1}

Following Vasicek (1977), the dynamics of $\left\{r_{t}\right\}$ under the risk-neutral probability measure $Q$ are

$$
d r_{t}=\alpha\left(\gamma-r_{t}\right) d t+\sigma_{r} d z_{1 t}
$$

where $\alpha, \gamma$, and $\sigma_{r}$ are constants and $\left\{z_{1 t}\right\}$ is a Standard Brownian Motion process. Vasicek shows that the dynamics of return of the default-free zero coupon bond $P\left(r_{t}, T\right)$ maturing at time $T$ are given at time $t$ under $Q$ by

$$
\frac{d P(r, t, T)}{P(r, t, T)}=r_{t} d t-\sigma_{P}(t, T) d z_{1 t}
$$

\footnotetext{
${ }^{2}$ Several other papers with similar structures have been written. We do not attempt an exhaustive survey of the pricing literature. Notably, papers such as Brennan and Schwartz (1984), Brennan, Detemple and Kalay (1989), Leland (1994), Leland and Toft (1996) and Merton (1974) have provided alternative conditions triggering default.
} 
where $\sigma_{P}(t, T)$ is a deterministic function of time given by

$$
\sigma_{P}(t, T)=\frac{\sigma_{r}}{\alpha}(1-\exp (-\alpha(T-t)))
$$

The value of the discount bond is given by

$$
\begin{aligned}
& P\left(r_{t}, T\right)=\exp \left[\frac{1}{\alpha}(1-\exp (-\alpha(T-t)))(R(\infty)-r)-(T-t) R(\infty)\right] \\
& \cdot \exp \left[-\frac{\sigma_{r}^{2}}{4 \alpha^{3}}(1-\exp (-\alpha(T-t)))^{2}\right], \quad t \leq T
\end{aligned}
$$

where $R(\infty)=\gamma+\frac{\sigma_{r} m_{r}}{\alpha}-\frac{1}{2} \frac{\sigma_{r}^{2}}{\alpha^{2}}$, and $m_{r}$ is the market price of interest rate risk, assumed to be a constant.

\section{Assumption 2}

Under $Q$, the value of the firm's assets follows the process

$$
\frac{d V_{t}}{V_{t}}=r_{t} \cdot d t+\sigma_{V}\left(\rho d z_{1 t}+\sqrt{1-\rho^{2}} d z_{2 t}\right)
$$

where $\left\{z_{2 t}\right\}$ is also a Standard Brownian Motion process, independent of $\left\{z_{1 t}\right\}$. The instantaneous correlation between $\frac{d V_{t}}{V_{t}}$ and $d r_{t}$ is $\rho$.

\section{Assumption 3}

The firm's asset process $\left\{V_{t}\right\}$ is independent of the capital structure of the firm. This is the standard assumption that the Modigliani-Miller Theorem holds. The assumption also implies that changes in capital structure, such as payments of coupons and principal, have no effect on $\left\{V_{t}\right\}$.

\section{Assumption 4}

There is senior and junior discount debt of $B$ and $D$ outstanding respectively; at the time of issuance, time 0 , each dollar of debt promises a final payment of $f_{S}$ at maturity if the firm is solvent, where $f_{S}=e^{y_{S} T}$, for $S=B, D$. The creditor owning these debts are protected upto fractions $0 \leq \alpha_{S} \leq 1$ of the promised payment at maturity through minimum net worth requirements: the creditors force the firm into filing for a reorganization when its value at time $t$ hits the time-varying default boundary $\nu_{t}$. If the firm defaults at time $t$, the bondholders receive $\alpha_{S} f_{S} P\left(r_{t}, t, T\right)$ in riskless securities that mature at $T$, to a value of $\alpha_{S} f_{S}$. In addition, equity holders can extract a fraction $\alpha_{E}$ of the value of the firm net of any bankruptcy costs. We assume that bankruptcy costs are a fraction $\Phi$ of the value of the firm. The default boundary, $\nu_{t}$, is given by

$$
\nu_{t}=\frac{1}{(1-\Phi)\left(1-\alpha_{E}\right)}\left[\alpha_{B} f_{B} B+\alpha_{D} f_{D} D\right] P\left(r_{t}, t, T\right) \equiv \nu P\left(r_{t}, T\right) .
$$

Due to the randomness of interest rates, the default boundary is stochastic. In this paper we do not make the important distinction between default and filing for a reorganization of liabilities. The protected fractions of 
the debts and the fraction of the value extracted by equity holders is determined by a bargaining process in bankruptcy, which is determined by a very complex set of rules (cf., for instance, Franks and Torous 1989). The fractions may be chosen to be consistent with rules of absolute priority, although this is not essential. ${ }^{3}$ If the firm files for bankruptcy prior to hitting the default boundary (its value is higher than that governed by minimum new worth), then all claims are paid in order of absolute priority. The values of different securities in bankruptcy is a very important topic for future research.

\section{Assumption 5}

A Leveraged Buyout (LBO) offer for the firm arrives with an exponential distribution with parameter $\lambda$. The density of an LBO at time $t$ is given by: $f(t \mid \lambda)=\lambda \exp (-\lambda t) .{ }^{4}$ The LBO arrival process is statistically independent of $d z_{1}$ and $d z_{2}$. In the leveraged buyout, the junior debt of the firm is increased by a fraction $\beta>1$. This will cause an increase in the threshold default boundary to $\nu_{t}^{L}$ given by

$$
\nu_{t}^{L}=\frac{1}{(1-\Phi)\left(1-\alpha_{E}\right)}\left[\alpha_{B} f_{B} B+\beta \alpha_{D} f_{D} D\right] P\left(r_{t}, T\right) \equiv \nu^{L} P\left(r_{t}, T\right)
$$

By Assumption 3, the LBO will not affect the value of the firm's assets, therefore, the probability of a firm filing for bankruptcy will increase after the transaction. The LBO raises the debt-to-equity ratio of the firm. The LBO will be consummated only if the value of the firm's assets at the time of the LBO arrival exceeds $\nu_{t}^{L}$, the post-LBO default boundary. The sudden possibility of a default gives the model some of the properties of the 'reduced' form approach of bond pricing (c.f., for instance Madan and Unal 1994, Duffie and Singleton 1995).

\section{Assumption 6}

We shall assume that if the value of the firms' assets at maturity is less than the face value of the debt, the firm will be able to raise additional debt, as long as its value exceeds the threshold default barrier. Under this assumption, the firm will not default on its debt at maturity as assumed in Briys and de Varenne (1997). The assumption will also hold for any coupon payments made at discrete intervals. Therefore, we are also assuming there are no 'flow' bankruptcy problems associated with coupon payments as in Anderson and Sundaresan (1996).

Following the literature (cf., for instance, Longstaff and Schwartz 1996, Briys and de Varenne 1997, Zhou 1997), we will use the Feynman-Kac Theorem (cf., for instance, Duffie 1992) to price the non-putable part of the bonds.

Define the process $\left\{q_{t}\right\}=\left\{\ln \left(\frac{V_{t}}{\nu_{t}}\right)\right\}$, where $\left\{\nu_{t}\right\}$ follows (6). Prior to an LBO, when $q_{t}$ hits zero, the firm defaults. After an LBO offer arrives, it will either be consummated or it will be passed up.

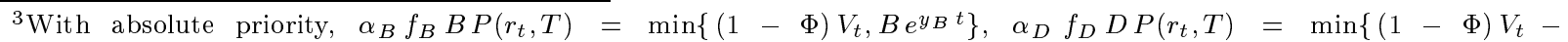
$\left.\alpha_{B} f_{B} B P\left(r_{t}, T\right), D e^{y_{D} t}\right\}$, and $\alpha_{E}(1-\Phi) V=(1-\Phi) V_{t}-\alpha_{B} f_{B} B P\left(r_{t}, T\right)-\alpha_{D} f_{D} D P\left(r_{t}, T\right)$.

${ }^{4}$ The exponential distribution is frequently used by statisticians to represent the distribution of time that elapses before the occurrence of some 'rare' event. If the events being considered occur in accordance with a Poisson process, then the waiting time until an event occurs and period of time between any two successive events will have an exponential distribution (cf., for instance, Degroot 1985).
} 
In the former case, the firm defaults when $q_{t}$ hits $\ln (l)$, where $l:=\frac{\alpha_{B} B+\beta \alpha_{D} D}{\alpha_{B} B+\alpha_{D} D}$. In the latter case, the default boundary does not change, and the firm will default when $q_{t}$ hits zero. The risk-neutral probability of default for a given asset value $V_{t}$ will be different for each of the three situations described; we will index the situation by $K ; K=P$, for the case before the LBO arrival, $K=L$, after the completion of an LBO, and, $K=U$, if the LBO offer arrives but is not consummated.

Lemma 1 Under the risk-neutral measure $Q$, the process $\left\{q_{t}\right\}$ is a diffusion process with drift $-\frac{1}{2} \sigma^{2}(t)$ and volatility $\sigma(t)$, where

$$
\sigma^{2}(t)=\left(\rho \sigma_{V}+\sigma_{P}(t, T)\right)^{2}+\left(1-\rho^{2}\right) \sigma_{v}^{2} \quad 0 \leq t \leq T
$$

where $\sigma_{P}(t, T)$ is given in (3). Let $\Sigma_{t_{1}, t_{2}}=\int_{t_{1}}^{t_{2}} \sigma^{2}(t) d t$. The probability of hitting zero under the risk-neutral measure $Q$ conditional on $q_{t_{1}}=x, \pi\left(q_{t}, t, T\right)$, is given by

$$
\pi\left(q_{t}, t_{1}, t_{2}\right)=N\left(\frac{-x+\frac{1}{2} \Sigma_{t_{1}, t_{2}}}{\sqrt{\Sigma_{t_{1}, t_{2}}}}\right)-e^{x} N\left(\frac{-x-\frac{1}{2} \Sigma_{t_{1}, t_{2}}}{\sqrt{\Sigma_{t_{1}, t_{2}}}}\right)
$$

The density of the hitting time conditional on $q_{t_{1}}=x$ is given by

$$
\pi^{\prime}\left(q_{t}, t_{1}, t_{2}\right)=x\left(\sigma\left(t_{2}\right)^{2}\left(t_{2}-t_{1}\right)^{3}\right)^{-\frac{1}{2}} n\left(\frac{x-\frac{1}{2} \Sigma_{t_{1}, t_{2}}}{\sqrt{\Sigma_{t_{1}, t_{2}}}}\right) .
$$

The transition density of $\left\{q_{t}\right\}$ absorbed at zero is given by

$\operatorname{Prob}\left(q_{t_{2}}=y \mid q_{t_{1}}=x, \min _{0 \leq s \leq t_{2}} q_{s}>0\right):=p^{a}\left(x, y, t_{1}, t_{2}\right)=n\left(\frac{y-x+\frac{1}{2} \Sigma_{t_{1}, t_{2}}}{\sqrt{\Sigma_{t_{1}, t_{2}}}}\right)-e^{x} n\left(\frac{y+x+\frac{1}{2} \Sigma_{t_{1}, t_{2}}}{\sqrt{\Sigma_{t_{1}, t_{2}}}}\right)$

$N(\cdot)$ and $n(\cdot)$ are the c.d.f. and the density of a standard normal random variable, $\Sigma_{t_{1}, t_{2}}$ is computed in (8), and $P\left(r_{t}, T\right)$, the price of a riskless discount bond, is as in (4).

Proof. (1), (2), (5) and (6) together imply that

$$
\frac{d V_{t}}{V_{t}}-\frac{d \nu_{t}}{\nu_{t}}=\sigma_{V}\left(\rho d z_{1 t}+\sqrt{1-\rho^{2}} d z_{2 t}\right)+\sigma_{P}(t, T) d z_{1 t}
$$

Now applying Ito's Lemma to the process $\left\{\ln \frac{V_{t}}{\nu_{t}}\right\}$, implies the distribution as stated and the variance as in (8). Let $\tau_{q, 0}$ be the first time $\left\{q_{t}\right\}$ hits 0 - the asset value hits the default boundary. Now standard results on hitting times and the Time Change theorem (to convert probabilities with time $t$ to time $\sigma(t)$ ) imply (9), (10), and (11) (for completely analogous results, see Briys and de Varenne 1997). For further literature on hitting times see Harrison (1985).

We next characterize prices of bonds after the arrival of the LBO offer. The prices naturally depend on whether or not the LBO was consummated. 
Lemma 2 If the LBO is not consummated, then the price of a non-putable bond of seniority $S$ maturing at $T$ at time $t$, equals

$$
P_{S}^{U}\left(V_{t}, \nu_{t}, \nu_{t}^{L}, r_{t}, t, T\right)=P\left(r_{t}, T\right)\left[1+\pi^{U}\left(V_{t}, \nu_{t}, t, T\right)\left(\alpha_{S}-1\right)\right] f_{S},
$$

for $S=B, D$, where $\pi^{U}\left(V_{t}, \nu_{t}, t, T\right)=\pi\left(\frac{V_{t}}{\nu_{t}}, t, T\right)$ is defined in (9). If the LBO is consummated, then the price of a non-putable bond of seniority $S$ maturing at $T$ at time $t$, equals

$$
P_{S}^{L}\left(V_{t}, \nu_{t}, \nu_{t}^{L}, r_{t}, t, T\right)=P\left(r_{t}, T\right)\left[1+\pi^{L}\left(V_{t}, \nu_{t}^{L}, t, T\right)\left(\alpha_{S}-1\right)\right] f_{S},
$$

for $S=B, D$, where $\pi^{L}\left(V_{t}, \nu_{t}^{L}, t, T\right)=\pi\left(\frac{V_{t}}{\nu_{t}^{L}}, t, T\right)$ is defined in (9).

Proof. The Feynman-Kac solution (c.f., for instance, Duffie 1992) implies that

$$
P_{D}=E^{Q}\left[\exp \left(-\int_{0}^{T} r_{s} d s\right)\left[\mathbf{1}_{\left\{\tau_{q, 0} \leq T\right\}} \alpha_{D}+\mathbf{1}_{\left\{\tau_{q, 0}>T\right\}} 1\right]\right],
$$

If the LBO is not consummated, then the default boundary is $\nu_{t}$ and therefore, the probability of default is $\pi^{U}\left(V_{t}, \nu_{t}, t, T\right)=\pi\left(\frac{V_{t}}{\nu_{t}}, t, T\right)$ where $\pi\left(\frac{V_{t}}{\nu_{t}}, t, T\right)$ is provided in Lemma 1. Taking expectations, using $\pi^{U}\left(V_{t}, \nu_{t}, t, T\right)$ as the probability of default implies (12). Similarly, if the LBO is consummated, then the default boundary increases to $\nu_{t}^{L}$. Define the process $\left\{q_{t}^{L}\right\}=\left\{\frac{V_{t}}{\nu_{t}^{L}}\right\}$; conditional on $q_{t}^{L}$, the process has the same law as $\left\{q_{t}\right\}$, implying that $\pi^{L}\left(V_{t}, \nu_{t}, t, T\right)=\pi\left(\frac{V_{t}}{\nu_{t}^{L}}, t, T\right)$. Again taking expectations implies (13).

We next characterize the probability of default when there is a potential LBO threat to the firm.

Lemma 3 Before the arrival of an LBO offer the price of a non-putable bond of seniority S, maturing at $T$, at time $t$, equals

$$
P_{S}^{P}\left(V_{t}, r_{t}, \nu_{t}, \nu_{t}^{L}, t, T\right)=f_{B} P\left(r_{t}, T\right)\left[1+\pi^{P}\left(\frac{V_{t}}{\nu_{t}}, \nu_{t}^{L}, t, T\right)\left(\alpha_{S}-1\right)\right]
$$

where $\pi^{P}\left(q_{t}, \nu_{t}^{L}, t, T\right)$, the conditional probability of default by $T$ under the risk-neutral measure $Q$, is written as the sum of the probabilities of four mutually exclusive events $A, B, C, D$ whose conditional probabilities are

$$
\begin{aligned}
\pi^{A}\left(q_{t}, \nu_{t}^{L}, t, T\right) & =\int_{t}^{T}\left[\lambda \exp (-\lambda s) \pi\left(q_{t}, t, s\right)\right] d s \\
\pi^{B}\left(q_{t}, \nu_{t}^{L}, t, T\right) & =\int_{t}^{T} \int_{0}^{\ln (l)}\left[\lambda \exp (-\lambda s) p^{a}\left(q_{t}, y, t, s\right) \pi(y, s, T)\right] d y d t \\
\pi^{C}\left(q_{t}, \nu_{t}^{L}, t, T\right) & =\int_{t}^{T} \int_{\ln (l)}^{\infty}\left[\lambda \exp (-\lambda s) p^{a}\left(q_{t}, y, t, s\right) \pi(y-\ln (l), s, T)\right] d y d t \\
\pi^{D}\left(q_{t}, \nu_{t}^{L}, t, T\right) & =\exp (-\lambda(T-t)) \pi\left(q_{t}, t, T\right)
\end{aligned}
$$


where $\pi\left(q_{t}, t, s\right)$ is given in (9), $p^{a}\left(q_{t}, y, t, s\right)$ as given in (11) and $l:=\frac{\alpha_{B} B+\beta \alpha_{D} D}{\alpha_{B} B+\alpha_{D} D}$.

The proof is in the appendix. The probabilities above involve integrating the c.d.f. of the Normal distribution - for which there is no closed-form; nevertheless, the numerical integration is completely straightforward and can be performed in a negligible amount of time on a modern computer. We illustrate the Lemma with some sample paths that lead to defaults of Type A, B and C in Figure 3 . Lemmas 3 and 2 characterize the probability of default before and after an LBO. Ratings set by credit rating agencies, associate ratings with probabilities of default, therefore the probabilities calculated are sufficient for the rating.

We now provide a characterization of the costs of bankruptcy upto period $T$ : since bankruptcy costs are a fixed proportion $\Phi$ of the value of the firm at bankruptcy, and the firm defaults when its value hits $\nu_{t}$ before an LBO or $\nu_{t}^{L}$ after the LBO, the expected costs of bankruptcy up to period $T$, can be evaluated by the same formulas above for pricing bonds.

Lemma 4 Let the value of the firm be $V_{t}$, then expected bankruptcy costs up to period $T$, discounted to $t$, are given by $\mathcal{B}^{K}\left(V_{t}, r_{t}, \nu_{t}, \nu_{t}^{L}, t, T\right) P\left(r_{t}, t, T\right)$ in situation $K$, where

$$
\mathcal{B}^{P}\left(V_{t}, r_{t}, \nu_{t}, \nu_{t}^{L}, t, T\right)=\left[\Phi\left[\pi^{P}\left(\frac{V_{t}}{\nu_{t}}, t, T\right)-\pi^{C}\left(\frac{V_{t}}{\nu_{t}}, t, T\right)\right] \nu+\pi^{C}\left(\frac{V_{t}}{\nu_{t}}, t, T\right) \nu^{L}\right]
$$

prior to the arrival of an LBO offer, to

$$
\mathcal{B}^{L}\left(V_{t}, r_{t}, \nu_{t}, \nu_{t}^{L}, t, T\right)=\left[\Phi \pi\left(\frac{V_{t}}{\nu_{t}^{L}}, t, T\right) \nu^{L}\right]
$$

after a successful LBO transaction, and by

$$
\mathcal{B}^{U}\left(V_{t}, r_{t}, \nu_{t}, \nu_{t}^{L}, t, T\right)=\Phi \pi\left(\frac{V_{t}}{\nu}, t, T\right) \nu
$$

after an unsuccessful LBO transaction, where $\pi\left(\frac{V_{t}}{\nu_{t}}, t, T\right)$ and $\pi^{P}\left(\frac{V_{t}}{\nu_{t}}, t, T\right)$ are given in Lemmas 2 and 3 respectively.

Proof. The default boundaries before and after the LBO offer arrival as given in (6) and (7) respectively. Before the LBO offer arrival, the transition density function for the $\left\{q_{t}\right\} \equiv\left\{\frac{V_{t}}{\nu_{t}}\right\}$ process is $\pi^{P}\left(q_{t}, \nu_{t}^{L}, t, T\right)$. The costs are higher for defaults of Type C (see Lemma 3). Taking expectations implies (19). Since there is only one LBO offer possible, after an offer arrival, the transition density function is $\pi\left(q_{t}, t, T\right)$. Again, taking expectations yields (20) if the LBO was was successful, and (21) if was unsuccessful. 


\section{The Put Induced Crisis}

The firm is assumed to be in an immediate financial crisis in Period $\tau_{P}$ : it has $D$ of junior putable bonds outstanding that will be exercised if the company's debt rating falls below a pre-specified threshold level and has effectively liquid assets smaller than the amount of debt to be paid back to the putable bondholders. ${ }^{5}$ The firm also has $B$ of senior non-putable debt (this might be all bank debt) and $D^{N}$ of junior non-putable debt. It is assumed that the firm's current rating (bond price) is close at the threshold rating (exercise price). The equity holders of the firm are assumed to be represented collectively by the management and shall be referred to as the 'firm'. The firm enters into a bargaining process with the putable bondholders in an attempt to buy back the put options and hence delay paying back the debt. It is assumed that all the putable bondholders are fully cognizant of the balance sheet of the company - and therefore there is a complete information bargaining problem. If the firm fails to negotiate a settlement to buy out the put options on the debt, and the bondholders put their bonds, then it must file for a reorganization of its liabilities.

The putable bonds are exercisable at par when its credit rating hits a prespecified level; it can be alternatively assumed that the bonds become exercisable when the bond price or some other observed variable that captures a salient aspect of the firm's credit quality hits some prespecified level. In recent years several putable bonds have been issued that are exercisable when the firm is purchased by a buyer through a leveraged buyout transaction. Moody's associate probabilities of default with each rating. In this model, by Lemmas 2 and 3, the probability of default is a continuous function of the value of its assets, and therefore, puts are exercisable when the value hits $\underline{v}^{P}, \underline{v}^{L}$ or $\underline{v}_{U}$ under situations $P, L$ or $U$ respectively. In this and all sections upto Section se:prior we shall assume that the value of the firm's assets has just hit on one these exercise boundaries, and therefore the puts are immediately exercisable. The pricing of the debt is as described in Section 3. The senior bondholders have written covenants on the activities of the firm. The covenant is summarized in the next assumption.

\section{Assumption 7}

If the firm accelerates the payments on more than a $\mathcal{T}$ of outstanding putable bonds (a trigger amount), then it is forced into filing for a reorganization of all its liabilities. If the firm files before its asset value hits the default boundary boundary as defined in (6) (or (7) after a successful LBO), then the recoveries of the various claim holders are made in order of absolute priority. The sequence of events in laid out in Figure 4. Consistent with the assumptions on payouts in bankruptcy, it is assumed that payments at the time the bonds are put, $\tau_{P}$, are made in riskless securities that mature at $T$ :

$$
B_{\tau_{P} F}\left(V_{\tau_{P}}, r_{\tau_{P}}, T\right)=\min \left\{(1-\Phi) V_{\tau_{P}}, B f_{B} P\left(r_{\tau_{P}}, T\right)\right\}
$$

\footnotetext{
${ }^{5}$ The amount of cash and securities on the balance sheet might not correspond to the effective liquidity of the company. Often, covenants written on the firm's bank debt restrict the use of this cash in distress situations.
} 


$$
\begin{aligned}
D_{\tau_{P}, F}^{N}\left(V_{\tau_{P}}, r_{\tau_{P}}, T\right) & =\frac{D^{N}}{D+D^{N}} \min \left\{(1-\Phi) V_{\tau_{P}}-B_{\tau_{P} F}, D f_{D} P\left(r_{\tau_{P}}, T\right)\right\}, \\
D_{\tau_{P}, F}\left(V_{\tau_{P}}, r_{\tau_{P}}, T\right) & =\frac{D}{D+D^{N}} \min \left\{(1-\Phi) V_{\tau_{P}}-B_{\tau_{P} F}, D f_{D} P\left(r_{\tau_{P}}, T\right)\right\}, \\
E_{\tau_{P} F}\left(V_{\tau_{P}}, r_{\tau_{P}}, T\right) & =V_{\tau_{P}}-B_{\tau_{P} F}-D_{\tau_{P} F},
\end{aligned}
$$

for senior debt $B$, junior non-putable debt $D^{N}$, junior putable debt $D$ and equity $E$.

If the company is able to negotiate a settlement to buy back enough of the options, it needs immediate financing of $W$, which comprises of $X_{C}$ to pay for the options, and $D_{P}$ to pay for the putable debt that is put (an agreement with some of the bondholders might be sufficient to stave off an immediate reorganization). The firms effective liquidity constrains it to letting $D_{P} \leq \mathcal{T}$, the trigger level. At the maturity of the debt $T$, the firm will either be 'insolvent' with probability $\pi^{K}$ due to poor performance, or it is 'solvent' with probability $1-\pi^{K}$, when the situation is $K=P, L, U$ as described in Section 3, and the probabilities, $\Pi^{K}$, are as in Lemmas 2 and 3. The payoffs of the different liabilities in insolvency is as described in Section 3. A flow chart describing the crisis is displayed in Figure 4.

The immediate financing need of $\mathcal{L}$ can be achieved through one of two methods: 1) The firm can issue equity; 2) A new bail-out loan. It is assumed that the bail-out loan is unprotected $\left(\alpha_{L}=0\right)$, and therefore its issuance does not change the default boundary of the firm. It is evident that if the new loan is priced at par $\left(P_{L}=1\right)$, and there are no distress costs of issuing equity, the firm shall be indifferent between raising debt and equity; even though quite standard, this is formally shown below.

Lemma 5 If the bail-out loan is made at par $\left(P_{L}^{K}=1\right)$, for $K=P, L, U$, and equity can be issued at no distress-costs, then equity holders are indifferent to the method of financing.

Proof. Let the value of the equity holders with the bail-out loan priced at par be $v_{L}^{K}=V-\mathcal{B}^{K}-B P_{B}^{K}-$ $D P_{D}^{K}-\mathcal{L}$ (for notational simplicity, time subscripts and arguments of the pricing functions have been left out), for $K=P, L, U$. The pricing functions $P_{D}^{K}$ and $P_{B}^{K}$ are given in Lemmas 2 and 3 and expected bankruptcy costs are given in Lemma 4. Similarly, let $v_{E}^{K}=V-\mathcal{B}^{K}-B P_{B}^{K}-D P_{D}^{K}$ be the value of the equity holders under equity financing. If equity can be issued under no distress costs, then a fraction $\epsilon$ of the ownership is sold to new equity holders satisfying $\epsilon v_{E}^{K}=\mathcal{L}$. Then, the value to the ex-ante shareholders equals $(1-\epsilon) v_{E}^{K}$, which is easily seen to equal $v_{L}^{K}$.

Intuitively, because the bail-out loan is senior to equity, the residual claim of the current equity holders will be the same for each of the two methods. Since it is unlikely that the distress costs of equity at the time of a financial crisis are non-zero, we shall assume that the financing need is met through a bail-out loan. The payoffs at maturity for the different classes of creditors are as described in Section 3; each creditor receives $f_{S}=e^{y_{S} T}$ at maturity if there is no default, and $\alpha_{S} f_{S}$ if default occurs prior to $T$ (Assumptions 3 and 5).

\section{Condition 1}


The putable bonds holders make full recovery of face value and accrued interest if the firm files for a reorganization of its liabilities at a value of assets higher than the threshold value:

$$
D_{\tau_{P}, F}\left(V_{\tau_{P}}, r_{\tau_{P}}, T\right) \geq D f_{D} P\left(r_{\tau_{P}}, T\right)
$$

where $D_{\tau_{P}, F}$ is defined in (24); the condition is equivalent to $(1-\Phi) V_{\tau_{P}} \geq B f_{B} P\left(r_{\tau_{P}}, T\right)+\left(D^{N}+\right.$ D) $f_{D} P\left(r_{\tau_{P}}, T\right)$.

Condition 1 is needed for the existence of a solution to the bargaining problem between the putable bondholders and the firm (to be discussed below). It will be shown that if the condition holds, then the value of pure bondholder coalitions is monotonically increasing in the size of the coalition. Conversely, it will be shown by an example that if the condition is violated, then the proposed non-cooperative solution will not belong to the core of the bargaining game (to be defined). If the condition is violated, then there will a breakdown of negotiations between the putable bondholders and equityholders leading to an exercise of the options and an immediate reorganization of the liabilities of the firm. It will also be seen that the assumption is sufficiently strong to imply that collectively the putable bondholders and the firm have a larger 'pie' to share between them by negotiating a settlement than in an immediate reorganization when the rating of the firm hits speculative grade.

Let us define the function $v_{\tau_{P}}^{K}(S)$ to be the value of the claims of a coalition of players $S \subset I$, when all players make coalitionally optimal decisions, where $I$ is the set of all players in the game, the situation of the game is $K$ for $K=P, L, U$, and $\tau_{P}$ denotes the time at which the bonds become putable. We assume that the equity holders are collectively represented by the management, also called the 'firm'. We abuse notation slightly to let $v_{\tau_{P}}^{K}\left(D_{S}\right)$ to be the market value of a set $S$ of putable bondholders, and $v_{\tau_{P}}^{K}\left(E \cup D_{S}\right)$ the market value of the equity holders and a set $S$ of putable bondholders.

Let $C$ be the set of bondholders that decide to sell their options back to the company and $P$ be the set of bondholders that decide to put their bonds, at the time when the options first become exercisable. If the bondholders do not put their bonds, then the value of their claims is $P_{D}^{K}$ per dollar of debt. Therefore, each bondholder not cooperating with the firm has a dominant strategy of putting his bonds when $\frac{D_{\tau_{P} F}}{D}>P_{D}^{K}$. Under Condition 1, they receive $f_{B} P\left(r_{\tau_{P}}, T\right)$ per dollar of debt in each situation, which is larger than $P_{D}^{K}$ as long as the probability of default is positive (see Lemmas 2 and 3); therefore,

$$
\begin{aligned}
v_{\tau_{P}}^{K}\left(D_{P}\right) & =D_{P} f_{B} P\left(r_{\tau_{P}}, T\right) & \text { when } D_{P} \leq \mathcal{T} \\
& =\frac{D_{P}}{D} \cdot D_{\tau_{P} F}=D_{P} f_{B} P\left(r_{\tau_{P}}, T\right) . & \text { when } D_{P}>\mathcal{T}
\end{aligned}
$$

Define the functions

$$
\bar{v}^{K}\left(V_{\tau_{P}}, \nu_{\tau_{P}}, \nu_{\tau_{P}}^{L}, r_{\tau_{P}}, \tau_{p}, T\right)=V_{\tau_{P}}-\mathcal{B}_{\tau_{P}}^{K}\left(V_{\tau_{P}}, \nu_{\tau_{P}}, \nu_{\tau_{P}}^{L}, r_{\tau_{P}}, \tau_{p}, T\right)-B P_{B}^{K}\left(V_{\tau_{P}}, \nu_{\tau_{P}}, \nu_{\tau_{P}}^{L}, r_{\tau_{P}}, \tau_{p}, T\right)
$$




$$
-\quad D^{N} P_{D}^{K}\left(V_{\tau_{P}}, \nu_{\tau_{P}}, \nu_{\tau_{P}}^{L}, r_{\tau_{P}}, \tau_{p}, T\right)
$$

for $K=P, L, U$ where the bankruptcy cost functions are given in (19),(20), and (21) respectively, and the pricing functions are in (14), (13), and (12). The function $\bar{v}^{K}$ is the size of the 'pie' to be shared between the equity holders and the putable bondholders in the situation $K$. The total value to divide between the firm and the putable bondholders is given by the value of the assets less the expected costs of bankruptcy upto period $T$ and the payments to senior and other junior putable debtholders.

To simplify the notation, from now on we shall omit the arguments of the functions $\bar{v}, P^{K}, E_{\tau_{P} F}$, $D_{\tau_{P} F}$ and $\mathcal{B}^{K}$. For example, we shall write $\bar{v}^{K}\left(V_{\tau_{P}}, \nu_{\tau_{P}}, \nu_{\tau_{P}}^{L}, r_{\tau_{P}}, \tau_{p}, T\right)$ simply as $\bar{v}_{\tau_{P}}^{K}$. The market value of the claims of equity holders and the set of cooperating bondholders is given by

$$
\begin{aligned}
v_{\tau_{P}}^{K}\left(E \bigcup D_{C}\right)=\bar{v}_{\tau_{P}}^{K}-\mathcal{L}+X_{C} & =\bar{v}_{\tau_{P}}^{K}-D_{P} f_{B} P\left(r_{\tau_{P}}, T\right) \quad \text { when } D_{P} \leq \mathcal{T} \\
& =E_{\tau_{P}} F+D_{\tau_{P} F}, \quad \text { when } D_{P}>\mathcal{T} .
\end{aligned}
$$

$\mathcal{L}=D_{P}+X_{C}$, is the size of the bail-out loan needed by the firm immediately, and $X_{C}$ (a function of the same arguments $V_{\tau_{P}}, \nu_{\tau_{P}}, \nu_{\tau_{P}}^{L}, r_{\tau_{P}}, \tau_{p}$, and $\left.T\right)$ is the payment for the options. When $\left(D-D_{C}\right)>$ $\mathcal{T}$, non-cooperating bondholders put their bonds and force the firm is forced into filing for an immediate reorganization. $D_{\tau_{P} F}$ and $E_{\tau_{P} F}$ are given in (24) and (25).

Lemma 6 If Condition 1 holds, the firm is solvent and is in situation $K$ for $K=P, L, U$, then

$$
\bar{v}_{\tau_{P}}^{K}>E_{\tau_{P} F}+D_{\tau_{P} F} .
$$

Therefore, the value of resources to be shared by equity holders and putable bondholders if they successfully negotiate a settlement is larger than if the firm fails immediately.

The proof is in the appendix.

\section{$5 \quad$ Intrinsic and Strategic Values of the Options}

The solution concept to solve the bargaining problem between the firm and putable bondholders uses recent results on N-player sequential, perfect information, non-cooperative games by Hart and Mas-Colell (1996). The game is played following a multilateral meeting with the requirement of unanimity for agreement. Let $v(S)$ be a function that assigns to every subset $I$ of the set of players, of the game the total utility that coalition can attain if all its members agree. ${ }^{6}$

The N-person noncooperative game is defined as follows:

\footnotetext{
${ }^{6}$ If all player are risk-neutral, and have the same scaling function of money to utility, then, this equals the total resources to be shared by the players. Such a game is in the class of transferable utility games.
} 
In each round there is a set $S \subset I$ of "active" players, and a "proposer" $i \in S$. In the first round $S=I$. The proposer is chosen at random out of $S$, with all players in $S$ being equally likely to be selected. The proposer makes a "proposal" which is feasible, i.e. a payoff vector in $v(S)$. If all the members of $S$ accept it - they are asked in some pre specified order - then the game ends with these payoffs. If it is rejected by even one member of $S$, then we move to the next round where, with probability $\rho$, the set of active players is again $S$ and, with probability $1-\rho$, the proposer "drops out" and the set of active players becomes $S-\{i\}$. In the latter case the dropped out proposer $i$ gets a final payoff of 0. (Hart and Mas-Colell 1996).

The key modelling aspect is the specification of what happens if there is no agreement and, as a consequence, the game moves to a new stage. In the framework, the breakdown of negotiations is not an "all or nothing" matter. When a player leaves the game, the rest continue bargaining — albeit over a diminished "pie". The cost of delay in agreement is present in the form of the breakdown probability $1-\rho$.

Result 1 If all players are risk-neutral, Condition 1 holds, the value function is defined in (26), (27),(29), and(30) gives the value of coalitions when the firm and bondholders bargain over the value of the put options on the bonds in situation $K$, for $K=P, L, U$, and players follow the sequence of moves as described above, then the proposals made in the unique Stationary Subgame Perfect equilibrium of the game with transferable utility are accepted; the equilibrium payoff vector converges to the Shapley Value of the game (a cooperative game theory axiomatic solution) as $\rho \rightarrow 1$. The Shapley Value of player $i$ is:

$$
\phi_{\tau_{P}, I}^{i, K}=\sum_{S \subset I} \gamma(N, S) \cdot\left(v_{\tau_{P}}^{K}[s]-v_{\tau_{P}}^{K}[s-\{i\}]\right),
$$

where, $\gamma(N, S)=\frac{(|S|-1) !(N-S) !}{N !} ; S$ is a subset of the set of players I. If Condition 1 does not hold at the time of bargaining, then negotiations break down immediately, and each player get his payoff in bankruptcy.

The proof is in the appendix. The Shapley value is the average marginal value of a player, where the average results by imagining the random formation of a coalition of all the players, starting with a single member and adding one player at a time. Each player is then assigned his marginal contribution accruing to the coalition at the time of his admission. In this process of computing the expected value for an individual player all coalition formations are considered as equally likely. In Result 1, the random assignment of the first player, and the small probability of each player dropping out leads to the possibility of each coalition forming with equal probability.

We are interested in studying the relationship between the intrinsic and strategic values of options. Let the bonds become exercisable at time $\tau_{P}$, then the intrinsic value of the put options in situation $K$ for $K=P, L, U$ equals

$$
I V_{\tau_{P}}^{K}=\max \left\{f_{B} P\left(r_{\tau_{P}}, T\right)-P_{D}^{K}, 0\right\}=f_{B} P\left(r_{\tau_{P}}, T\right) \pi^{K}(\cdot, \cdot) \cdot\left(1-\alpha_{D}\right) .
$$


Under Condition 1, upon exercise, the put holder receives full recovery of principal plus accrued interest of $f_{B} P\left(r_{\tau_{P}}, T\right)$; the second equality follows from Lemmas (2) and (3). Since we have assumed that the nonputable debt of the firm trades freely in perfectly competitive markets at all times, we define the strategic value of the put options on the putable debt as the excess of the value of the player over the value of the nonputable debt. Therefore, at the time the options become exercisable, when the situation is $K$, and the set of players is $I$ the strategic value of the options of player $i$ equals

$$
S V_{\tau_{P} I}^{D_{i}, K}=\max \left\{\frac{\phi_{\tau_{P} I}^{D_{i}, K}}{D_{i}}-P_{D}^{K}, 0\right\}
$$

Lemma 7 Under Condition 1, $\phi_{\tau_{P}}^{D_{i}, K} D_{i} \geq f_{B} P\left(r_{\tau_{P}}, T\right)$. Therefore, the strategic value of the put option of a bondholder owning putable debt $D_{i}$ equals:

$$
S V_{\tau_{P} I}^{D_{i}, K}=\max \left\{\frac{\phi_{\tau_{P} I}^{D_{i}, K}}{D_{i}}-P_{D}^{K}, 0\right\}=\frac{\phi_{\tau_{P} I}^{D_{i}, K}}{D_{i}}-f_{D} P\left(r_{\tau_{P}}, T\right) \pi^{K}(\cdot, \cdot)
$$

where, $\pi^{K}(\cdot, \cdot)$ is the probability of default in situation $K$ as given in Lemmas 2 and 3.

The proof is in the appendix. The theory of bargaining has progressed rapidly in the past several years. The recent focus has been on non-cooperative approaches, completely defined by a particular sequence of moves (offers and replies) to be made over time in the course of negotiations, and then looking for noncooperative equilibrium in the game thus specified. One of the biggest breakthroughs for the 2-person bargaining game was made by Rubinstein (1982) who solved for a unique subgame perfect equilibrium in the 'alternating offers' model with an explicit cost of delay - modeled as a 'shrinking of the pie'. For more than two players, the Rubinstein model yields a folk-like theorem (a continuum of equilibria), if the solution concept is merely subgame perfection. Some examples of this and a survey of bargaining models are available in Sutton (1986). To push the analysis forward, theorists have concentrated on stationary subgame perfect equilibria - where strategies are such that the choice at each stage only depends on the current state of the game. For transferable utility games, the convergence of stationary equilibrium in the N-player bargaining problem to the Shapley Value have been found (in addition to the model of Hart and Mas-Colell) with different sets of rules by Harsanyi (1981) and Winter (1994). The Hart and Mas-Colell model is particularly appealing when players all meet together to negotiate (some others model multiple bilateral negotiations), and partial breakdown (by some players is allowable). Since the same solution obtains under a variety of rules, we find it comfortable to posit the Shapley Value as the solution.

\section{Equally Sized Bondholders}

In the case where there are $N$ bondholders each holding $\frac{D}{N}$ of the face value of putable debt, the notation is further simplified by defining $v_{\tau_{P}}^{K}\left(E \cup D_{n}\right)$, the total expected amount that can be distributed between the 
equity holders and $n$ cooperating bondholders. Using (29) and (30), one obtains

$$
\begin{aligned}
v_{\tau_{P}}^{K}\left(E \cup D_{n}\right) & =\bar{v}_{\tau_{P}}^{K}-\frac{N-n}{N} \cdot D f_{D} P\left(r_{\tau_{P}}, T\right), & \text { when } \frac{N-n}{N} D \leq \mathcal{T}, \\
& =E_{\tau_{P} F}+\frac{n}{N} \cdot D_{\tau_{P} F}, \quad \text { when } & \frac{N-n}{N} D>\mathcal{T} .
\end{aligned}
$$

Using (26) and (27) for pure bondholder coalitions,

$$
\begin{aligned}
v_{\tau_{P}}^{K}\left(D_{n}\right) & =\frac{n}{N} D f_{B} P\left(r_{\tau_{P}}, T\right) & \text { when } \frac{n}{N} \leq \mathcal{T} D \\
& =\frac{n}{N} D_{\tau_{P} F}, & \text { when } \frac{n}{N}>\mathcal{T} D
\end{aligned}
$$

There are $N+1$ players in the game, with $N$ bondholders. Then from (31), the Shapley Value of the firm for this special case is

$$
\begin{aligned}
\phi_{N, \tau_{P}}^{E, K} & =\sum_{n=0}^{N} \sum_{C:|C|=n} \gamma(N+1, n+1) \cdot\left(v_{\tau_{P}}^{K}\left(E \cup D_{C}\right)-v_{\tau_{P}}^{K}\left(D_{C}\right)\right) \\
& =\frac{1}{N+1} \cdot \sum_{n=0}^{N}\left(v_{\tau_{P}}^{K}\left(E \cup D_{n}\right)-v_{\tau_{P}}^{K}\left(D_{n}\right)\right)
\end{aligned}
$$

since there are $\frac{N !}{(N-n) ! n !}$ coalitions with $n$ bondholders.

Result 2 The Shapley Value of the equity holders when there are $N$ equally sized bondholders, and Condition 1 holds is given by

$$
\phi_{N, \tau_{P}}^{E, K}=E_{\tau_{P} F} \cdot \frac{N-M^{c}+1}{N+1}+\frac{M^{c}}{N+1} \cdot\left[\bar{v}_{\tau_{P}}^{K}-D f_{D} P\left(r_{\tau_{P}}, T\right)\right]
$$

$M^{c}(\mathcal{T}, N)=\lfloor N \mathcal{T}\rfloor+1$ is the smallest number of bondholders that can force the company into a reorganization. The Shapley Value of each bondholder is given by $\phi_{N, \tau_{P}}^{D_{i}, K}=\frac{1}{N} \cdot\left(\bar{v}-\phi_{N}^{E}\right)$.

Proof. Substituting (35), (36), (37), and (38) into (39) implies

$$
\begin{aligned}
\phi_{N, \tau_{P}}^{E, K} & =\frac{1}{N+1} \cdot\left[\sum_{n=0}^{N-M^{c}} E_{\tau_{P} F}+\frac{n}{N} D_{\tau_{P} F}+\sum_{n=N-M^{c}+1}^{N} \bar{v}_{\tau_{P}}^{K}-\frac{N-n}{N} D f_{D} P\left(r_{\tau_{P}}, T\right)\right. \\
& \left.-\sum_{n=0}^{M^{c}-1} \frac{n}{N} D f_{D} P\left(r_{\tau_{P}}, T\right)-\sum_{n=M^{c}}^{N} \frac{n}{N} D_{\tau_{P} F}\right] .
\end{aligned}
$$

Now collecting terms implies that

$$
\phi_{N, \tau_{P}}^{E, K}=E_{\tau_{P} F} \cdot \frac{N-M^{c}+1}{N+1}+\frac{M^{c}}{N+1} \cdot\left[\bar{v}_{\tau_{P}}^{K}-D f_{D} P\left(r_{\tau_{P}}, T\right) \cdot \frac{M^{c}-1}{N}-D_{\tau_{P} F} \cdot \frac{N-M^{c}+1}{N}\right]
$$

If Condition 1 holds, then $D_{\tau_{P} F}=D f_{D} P\left(r_{\tau_{P}}, T\right)$ and $\phi_{N, \tau_{P}}^{D_{i}, K}$ is given by (40). 
The proportion $\frac{M^{c}}{N+1}$ represents the proportion of all coalitions (including the firm) in which the firm reaches a settlement and avoids bankruptcy. ${ }^{7}$ When there are $N$ equally-sized bondholders it is a sufficient statistic for the bargaining strength of the firm relative to the putable bondholders. Since the fraction is non-monotonic in the number of putable bondholders, it leads to a non-monotonicity in the bargaining strength of the firm. We illustrate the phenomenon with an example. which is illustrated in Figure 5 .

\section{Example 1}

The following parameters describe the problem at the time the bonds first become putable: $\bar{v}=3, D=.5$, $f_{D}=2.5, P\left(r_{\tau_{P}}, T\right)=.4, D_{\tau_{P} F}=.5, T=.1, E_{\tau_{P} F}=2$, and $\pi_{T}=.25$. Using Lemma 2 we calculate the strategic value of the firm, the strategic value of each bondholder and the payment for the option as defined in (33) for $N=1, \cdots, 20$. The three values along with the ratio $\frac{M^{c}}{N+1}$ are displayed in the three panels of Figure 5. As seen in the figure, the strategic values of the firm and the bondholders vary positively and negatively respectively with the ratio. Of note is the fact that the strategic value of the option can be signifantly larger than one. For example when $N=5$, the strategic value of the firm equals 1.83 , and that of the bondholders equal 1.17. Therefore each bondholder has a strategic value of .23. Since each bondholder owns .1 of putable debt, the value of the option by (33) equals 2.08 . The ratio $\frac{M^{c}}{N+1}$ tends to $\frac{\mathcal{T}}{D}=.2$ as $N \rightarrow \infty$, thus providing a limiting value for the value of the firm.

Corollary 1 The limit of the equity holders value as the number of putable bondholders becomes large is:

$$
\begin{aligned}
\phi_{\infty}^{E} \equiv \lim _{N \rightarrow \infty} \phi_{N}^{E} & =E_{\tau_{P} F} \cdot\left(1-\frac{\mathcal{T}}{D}\right)+\frac{\mathcal{T}}{D} \cdot\left[\bar{v}_{\tau_{P}}^{K}-D f_{D} P\left(r_{\tau_{P}}, T\right)\right] \\
\phi_{\infty}^{D} \equiv \lim _{N \rightarrow \infty} \sum_{i=1}^{N} \phi_{N}^{D_{i}} & =\left(1-\frac{\mathcal{T}}{D}\right) \cdot\left(\bar{v}-E_{\tau_{P} F}\right)+\mathcal{T} f_{D} P\left(r_{\tau_{P}}, T\right)
\end{aligned}
$$

The proof is in the appendix.

Interpretation of Limiting Value: The form of the limiting bargaining value of the equity holders suggests that $\frac{\mathcal{T}}{D}$ can be interpreted as a probability. ${ }^{8}$ With infinitesimal bondholders there is a probability $1-\frac{\mathcal{T}}{D}$, of a coalition forming that will force the company into a reorganization. With the complementary probability $\frac{\mathcal{T}}{D}$, the company will purchase the options back from enough bondholders to avert a reorganization of the firm. Put slightly differently, the Shapley Value of a player is the average marginal contribution of the player across all possible coalitions. When each bondholder contributes an infinitesimal, the average and marginal contributions coincide, and the Shapley Value of each bondholder is simply his average contribution. See Ostroy (1984) for an elucidation of this point.

\footnotetext{
${ }^{7}\lfloor N \mathcal{T}\rfloor$, using the floor function, is the largest integer less than or equal to $N \mathcal{T}$. Note that $\left.\mid N \mathcal{T}\right\rfloor+1$ is not always equal to $=\lceil N \mathcal{T}\rceil$ (using the analogous ceiling function). For example when $\mathcal{T} / D=2 / 3$ and $N$ equals 3 , the former number equals 3 and the latter 2 . However, $D 2 / 3=\mathcal{T}$, therefore the smallest threatening coalition must have three bondholders.

${ }^{8}$ This is really only a pseudo probability, because in equilibrium the first proposer makes an offer that all players accept. It corresponds to the probability of a coalition forming in which the firm need not file for a reorganization when coalition formation is viewed as being random under the rules of the bargaining game defined in Section 5 .
} 
It is well known that as the number of players increases to infinity, the Shapley Value converges to the Walrasian equilibrium of the game. The limiting value obtained above is useful because it enables the pricing of covenants of debt in a perfectly competitive setting. It is seen that even with infinitesimal putable bondholders in a decentralized setting, such bondholders have joint threatening power.

\section{Corollary 2 Under Condition 1,}

$$
S V_{N, \tau_{P}}^{D_{i}, K}=\left(1-\alpha^{N}\right)\left[\frac{\bar{v}_{\tau_{P}}^{K}-E_{\tau_{P} F}}{D}-f_{D} P\left(r_{\tau_{P}}, T\right)\right]+I V_{N, \tau_{P}}^{D_{i}, K}
$$

where $\alpha^{N}=\frac{M^{C}(\mathcal{T}, N)}{N+1}$. The strategic value of the put options exceeds the intrinsic value, even when there are an infinite number of bondholders, as long as $\mathcal{T}<D$.

Proof. Using Result 2, and the definitions of intrinsic and strategic values as in (32) and (33),

$$
S V_{N, \tau_{P}}^{D_{i}, K}=\left(1-\alpha^{N}\right)\left[\frac{\bar{v}_{\tau_{P}}^{K}-E_{\tau_{P} F}}{D}-f_{D} P\left(r_{\tau_{P}}, T\right)\right]+f_{D} P\left(r_{\tau_{P}}, T\right) \pi^{K}(\cdot, \cdot)\left(1-\alpha_{D}\right),
$$

The intrinsic value of the options is $I V_{\tau_{P}}^{K}=f_{D} P\left(r_{\tau_{P}}, T\right) \pi^{K}(\cdot, \cdot)\left(1-\alpha_{D}\right)$. Under Condition 1 , the first term in (44) is positive, therefore, the strategic value exceeds the intrinsic value for all $N$ whenever $\alpha^{N}<1$. For $\mathcal{T}<D$, this is true for all $N$, even as $N \rightarrow \infty$.

Corollary 3 For $\frac{\mathcal{T}}{D} \leq .5$, the bargaining value of the firm is the highest when only one bondholder owns the entire putable debt.

Proof. From Lemma 2 the bargaining strength of the firm $\phi_{N}^{E}$ is increasing in the ratio $\frac{M^{c}}{N+1}$. We use the mathematical fact that $\frac{\lfloor\alpha N\rfloor+1}{N+1} \leq .5$ for $\alpha \leq .5$ and $N=1,2,3, \cdots$. Therefore $\phi_{N}^{E}$ is maximized for $N=1$.

For $\frac{\mathcal{T}}{D}>.5$, the optimal $N$ (from the point of view of the firm) can be greater than 1 , but we can only provide an approximate solution. The ratio $\frac{M^{c}}{N+1}$ is highest for the smallest integer $n$ satisfying $\left\lfloor n \frac{\mathcal{T}}{D}\right\rfloor+1=n \frac{\mathcal{T}}{D}$. For example for $\frac{T}{D}=.6, n=5$.

Some special cases of the game when there are $N$ equally sized bondholders are interesting to highlight different aspects of the solution:

Special Case 1: When $N=1$, and $\mathcal{T}<D, \phi_{1}^{E}=\frac{\bar{v}-D_{\tau_{P} F}}{2}+\frac{E_{\tau_{P} F}}{2}$, irrespective of the level of $\mathcal{T}$. In one of the two coalitions that can potentially be formed, the equity holders have a marginal value of $\bar{v}-D_{\tau_{P} F}$. In the other, the firm fails to purchase the options from the bondholder and therefore the firm contributes a marginal value equal to $E_{\tau_{P} F}$. Note that the same value results for a large range in values of $\mathcal{T}$; irrespective of $\mathcal{T}$, whenever the bondholder puts the company is forced into a reorganization. Generalizing, whenever $N$ is small enough so that $\frac{D}{N}>\mathcal{T}$, the same strategic values result for a trigger value satisfying $0<\frac{D}{N}<\mathcal{T}$. 
Special Case 2: For $\mathcal{T} \geq D, \phi_{N}^{E}=\bar{v}-D f_{D} P\left(r_{\tau_{P}}, T\right), \forall N$. Therefore, when there is no trigger level (all the puts can be exercised without forcing the company into a reorganization), the strategic value of the firm does not depend on the number of bondholders that own its debt. Without a liquidity problem, the bondholders have no threatening power and therefore the value of the firm does not depend on the number of bondholders. The strategic value of the bondholders equals the face value of the debt, and hence the strategic value of the put option, as defined in (34), equals the intrinsic value of the options.

Special Case 3: $\lim _{\mathcal{T} \rightarrow 0} \phi_{N}^{E}=E_{\tau_{P} F} \frac{N}{N+1}+\left(\bar{v}-D f_{D} P\left(r_{\tau_{P}}, T\right)\right) \frac{1}{N+1}$. In this case, each bondholder can unilaterally bankrupt the firm. Therefore, the firm obtains the same as any bondholder $\frac{1}{N+1}$ of the expected total resources in non-bankrupt states. When $N$ become large, the firms strategic value declines to $E_{\tau_{P} F}$, its residual value in an immediate reorganization.

Most theorists (for example, Aivazian and Callen 1983) have argued that a reasonable solution to a bargaining game between players prior to bankruptcy must be in the core of the game. We will shown with an example that the Shapley Value of the game described is not in the core if Condition 1 is violated. The core of a game in coalitional form with characteristic function $v$ and the set of players $I$ is defined as the set of allocations:

$$
\text { Core }[v]=\left\{x \in \mathcal{R}^{N} \mid \sum_{i \in I} x_{i}=v(N) \text { and } \sum_{i \in S} x_{i} \geq v(S) \forall S\right\}
$$

The core is the set of allocations that is coalitionally rational, i.e., no coalition of members can break away, and using only the resources of the coalition, provide each member a larger amount than the core allocation.

Example 2 (The Necessity of Condition 1)

The parameters of the problem are as follows: $\bar{v}_{\tau_{P}}=5.05, D=.6, D_{\tau_{P} F}=.1, T=.4$, $E_{\tau_{P} F}=0$, and $N=2$. Using Lemma 2 we find that $\phi_{1}^{E}=3.133$, and $\phi_{D_{i}}=.958$. The core allocations are described by: $x_{E} \geq 0 ; x_{D_{i}} \geq .3$ for $i=1,2 ; x_{E}+x_{D_{i}} \geq 4.75$ for $i=1,2 ; x_{D_{1}}+x_{D_{2}} \geq .1$; and $x_{E}+x_{D_{1}}+x_{D_{2}}=5.05$. The Shapley Values of the players, $\phi_{1}^{E}=3.133$, and $\phi_{D_{i}}=.958$ clearly does not satisfy $\phi_{E}+\phi_{D_{i}} \geq 4.75$.

\section{The Bargaining Strength of a Large Bondholder}

Large institutional lenders are fairly common in most borrowing arrangements. For example, the private placement of debt is often done through a lead lender. The lender takes on a large amount of the loan and often performs various tasks in servicing the loan for other lenders. We abstract from this monitoring function of the largest lender and focus our attention to the threatening power of the large lender relative to other lenders. Conditions under which the strategic value of the large lender is greater are provided below. 
Consider the potential coalitions that can be formed with $N$ bondholders of equal size collectively holding debt $D$, the large bondholder with debt $D^{1}$, and the equity holders. Throughout, $M^{0}(T, D, N)=$ $\min \left\{\left\lfloor\frac{T}{D} N\right\rfloor+1, N\right\}$ and $M^{1}\left(T, D, D^{1}, N\right)=\max \left\{\left\lfloor\frac{T-D^{1}}{D} N\right\rfloor+1,0\right\}$. To keep the notation simple, the arguments of these functions shall be left out below. $M^{0}$ is the smallest number of equally-sized bondholders that can collectively threaten the firm. $M^{1}$ is the smallest number of equally-sized bondholders that together with the large bondholder can put their bonds and force the firm into a reorganization. Obviously, $M^{1}<M^{0}$.

Lemma 8 The strategic value of the firm is given by:

$$
\begin{aligned}
\phi_{N}^{E} & =\frac{1}{(N+2)(N+1)}( \\
& +\sum_{m=0}^{N-M^{0}}\left(\frac{\frac{m}{N} D+D^{1}}{D+D^{1}} D_{\tau_{P} F}+E_{\tau_{P} F}\right) \cdot(m+1)+\sum_{N-M^{0}+1}^{N}\left(\bar{v}_{\tau_{P} F}-\left(\frac{N-m}{N} D f_{D} P\left(r_{\tau_{P}}, T\right)\right)\right) \cdot(m+1) \\
& \left.-\sum_{m=0}^{M^{1}-1}\left(\frac{m}{N} D+D^{1}\right) f_{D} P\left(r_{\tau_{P}}, T\right) \cdot(m+1)-\sum_{m=M^{1}}^{N}\left(\frac{\frac{m}{N} D+D^{1}}{D+D^{1}} D_{\tau_{P} F}\right) \cdot(m+1)\right) \\
& +\sum_{m=0}^{N-M^{1}}\left(\frac{\frac{m}{N} D}{D+D^{1}} D_{\tau_{P} F}+E_{\tau_{P} F}\right) \cdot(N+1-m)+\sum_{N-M^{1}+1}^{N}\left(\bar{v}_{\tau_{P}}-\left(D^{1}+\frac{N-m}{N} D\right) f_{D} P\left(r_{\tau_{P}}, T\right)\right) \cdot(N+1-m) \\
& \left.-\sum_{m=0}^{M^{0}-1} \frac{m}{N} D f_{D} P\left(r_{\tau_{P}}, T\right) \cdot(N+1-m)-\sum_{m=M^{0}}^{N}\left(\frac{\frac{m}{N} D}{D+D^{1}} D_{\tau_{P} F}+E_{\tau_{P} F}\right) \cdot(N+1-m)\right)
\end{aligned}
$$

The strategic value of the large bondholder is given by:

$$
\begin{aligned}
\phi_{N}^{D^{1}} & =\frac{1}{(N+2)(N+1)}( \\
& +\sum_{m=0}^{M^{1}-1}\left(\frac{m}{N} D+D^{1}\right) f_{D} P\left(r_{\tau_{P}}, T\right) \cdot(N-m+1)+\sum_{M^{1}}^{N}\left(\frac{\frac{m}{N} D+D^{1}}{D+D^{1}} D_{\tau_{P} F}\right) \cdot(N-m+1) \\
& -\sum_{m=0}^{M^{0}-1}\left(\frac{m}{N} D f_{D} P\left(r_{\tau_{P}}, T\right)\right) \cdot(N-m+1)-\sum_{m=M^{0}}^{N}\left(\frac{\frac{m}{N} D}{D+D^{1}} D_{\tau_{P} F}\right) \cdot(N-m+1) \\
& +\sum_{m=0}^{N-M^{0}}\left(\frac{\frac{m}{N} D+D^{1}}{D+D^{1}} D_{\tau_{P} F}+E_{\tau_{P} F}\right) \cdot(m+1)+\sum_{m=N-M^{0}+1}^{N}\left(\bar{v}_{\tau_{P}}-\left(\frac{N-m}{N} D f_{D} P\left(r_{\tau_{P}}, T\right)\right)\right) \cdot(m+1) \\
& \left.-\sum_{m=0}^{N-M^{1}}\left(\frac{\frac{m}{N} D}{D+D^{1}} D_{\tau_{P} F}+E_{\tau_{P} F}\right) \cdot(m+1)-\sum_{m=N-M^{1}+1}^{N}\left(\bar{v}_{\tau_{P}}-\left(\frac{N-m}{N} D+D^{1}\right) f_{D} P\left(r_{\tau_{P}}, T\right) \cdot(m+1)\right)\right)
\end{aligned}
$$

The value of each of the smaller bondholders equals: $\frac{\bar{v}_{\tau_{P}}-\phi^{E}-\phi^{D^{1}}}{N}$.

The summations in the two equations lead to long polynomials that can be easily written down using a symbolic mathematical program such as Mathematica. We have preferred to leave them in the current form because the solutions are more transparent for the reader under this form. 


\subsection{One Large and One Small Bondholder}

Does a putable bondholder owning large amounts of putable bonds necessarily have a higher strategic value per dollar of putable debt owned? Does a firm with one large and one small bondholder necessarily have a higher strategic value than another with the same amount of total putable debt split equally between two bondholders? We demonstrate in this section that the answer to both questions is 'No'. Conditions under which the statements holds true are provided.

\section{Example 3}

Suppose there is one large and one small bondholder holding $D^{1}$ and $D$ of putable debt respectively. The following parameters describe the problem: $\bar{v}_{\tau_{P}}=5, D=.3, D_{1}=.6, f_{D}=2.5, P\left(r_{\tau_{P}}, T\right)=.4$, $T=.1, E_{\tau_{P} F}=3$, and $\pi_{T}=.25$. Using Lemma 8, Figure 6 shows the strategic values for the large and small bondholders per dollar of debt and the strategic value of the firm when the trigger level of debt is allowed to vary between 0 and $D+D^{1}$. The values remain constant within three regions to be defined below but exhibit some important discontinuities as the trigger level moves from one region to the next. The three cases determine the relative bargaining strengths of the large and small bondholders and the firm. As is Lemma 2, the values of the players depend on the proportion of coalitions that can credibly threaten the company into a reorganization. The three distinct cases are:

Case (i): $T<D<D^{1}$. Each bondholder can unilaterally force the firm into a reorganization.

Case (ii): $D<T<D^{1}$. Only the large bondholder can unilaterally drive the firm into a reorganization.

Case (iii): $D<D^{1}<T$ but $D+D^{1}>T$. The large and the small bondholder can jointly (but not unilaterally) force the firm into a reorganization.

Cases (i) and (iii) are similar in that the small and the large bondholder can potentially be part of an identical number of coalitions that can lead to a reorganization of the firm. In Case (ii), the large bondholder can be involved in a larger number of successful coalitions; the coalition $E \bigcup D^{1}$ (the firm and large bondholder) does not have to file for reorganization but the coalition $E \bigcup D$ (the firm and large bondholder) is forced into it. Not surprisingly, Figure 6 shows that the strategic value per dollar of the large bondholder is substantially larger than that for the small bondholder. In Cases (i) and (iii) the strategic value per dollar of the small bondholders debt is larger. The reasoning is as follows; in coalitions in which the company files for reorganization, each dollar of debt - either of the large or the small bondholder has the same recovery, $\frac{1}{D+D^{1}} D_{\tau_{P} F}$. In coalitions in which reorganization is avoided, each dollar of the large bondholders debt contributes $\frac{\bar{\tau}_{\tau_{P}}}{D^{1}}$ of the total value and while each dollar of the small bondholder's debt contributes a larger $\frac{\bar{v}_{\tau_{P}}}{D}$ of the total value. Said simply, the cooperation of each lender is required for the players to jointly realize the 'pie' $\bar{v}_{\tau_{P}}$; therefore the smaller bondholder contributes more per dollar. Therefore, if the large and the small bondholders are involved in the same number of non-bankrupt coalitions, then the small bondholder has a higher strategic value per dollar. 
It is evident from Figure 6 that the value of the firm is non-decreasing in $\frac{T}{D+D^{1}}$. The value of the firm jumps up at .3 and .6. At these values of the trigger level of debt the game moves from Case (i) to Case (ii) at .3, and from Case (ii) to Case (iii) at .6, as described in the previous paragraph. At each of these points there is a discontinuous decrease in the proportion of lenders that can cause a reorganization.

To answer the second question stated at the beginning of this subsection, suppose $D<T<D^{1}$. Then, its value is $\phi^{E}=\frac{1}{3} v(E)+\frac{1}{3}\left(v\left(E \bigcup D \bigcup D^{1}\right)-v\left(D \bigcup D^{1}\right)\right)+\frac{1}{6} E_{\tau_{P} F}+\frac{1}{6}\left(\bar{v}_{\tau_{P}}-D-D^{1}\right)$. Suppose there is an identical firm with the putable debt $D+D^{1}$ held by two equally sized bondholders. Then the value of the firm equals $\phi^{E}=\frac{1}{3} v(E)+\frac{1}{3}\left(v\left(E \bigcup D \bigcup D^{1}\right)-v\left(D \bigcup D^{1}\right)\right)+\frac{1}{3} E_{\tau_{P} F}$, if $\frac{D+D^{1}}{2}>T$ and $\phi^{E}=\frac{1}{3} v(E)+\frac{1}{3}\left(v\left(E \bigcup D \bigcup D^{1}\right)-v\left(D \bigcup D^{1}\right)\right)+\frac{1}{3}\left(\bar{v}_{\tau_{P}}-D-D^{1}\right)$ if $\frac{D+D^{1}}{2}<T$. The first two terms in each situation are the same since the total amount of putable debt is constant. In the first case, the value is smaller than the situation where there is one large bondholder and in the second, the value is larger.

\subsection{One Large and Several Small Bondholders}

When $D<D^{1}$, the analysis closely follows that of the case when there is one large and one small bondholder. For example, when $D<T D^{1}$, then the strategic value of the firm and the large players do not depend on $N$, the number of small bondholders, because these players are never pivotal to any threatening coalition. When $D<D^{1}$, the analysis can be divided into cases similar to those in the previous subsection.

\section{Example 4}

Suppose there is one large and one small bondholder holding $D^{1}$ and $D$ of putable debt respectively. The following parameters describe the problem: $\bar{v}_{\tau_{P}}=5, D=.6, D_{1}=.3, f_{D}=2.5, P\left(r_{\tau_{P}}, T\right)=.4$, $T=.1, E_{\tau_{P} F}=3$, and $\pi_{T}=.4$. Using Lemma 8, Figure 6 shows the strategic values for the large and small bondholders per dollar of debt and the strategic value of the firm when the trigger level of debt is allowed to vary between 0 and $D+D^{1}$.

Figure 7 shows the relative bargaining powers of the players forthree different cases. Just as in Lemma 2, the values of the players depend on the proportion of coalitions that can credibly threaten the company into a reorganization. In Case (i), $T<D^{1}<D$, therefore, a collection of atleast $M^{0}$ bondholders (defined above), the large bondholder alone or the large bondholder and $M^{1}$ bondholders can credibly threaten the firm. As the debt $D$ is divided among a large number of bondholders, a larger number of threatening coalitions can be formed. Therefore, as $N$ increases, the value of the large relative to small bondholders tends to decrease (the non-monotonicity as discussed previously applies). In Case (ii), $D^{1}<T<D$ and (iii), $D^{1}<D<T$, the large bondholder cannot trigger a bankruptcy on his own. Cooperation with some amount of putable debt is needed. As $N$ increases, the potential threatening coalitions he is a part of increase, therefore increasing his relative value with the number of small bondholders. 


\section{Bargaining Problem at the time of Kmart's Poison Put Crisis}

All but one parameter of the model needed to calculate strategic values using Lemma 2 have either been obtained from publicly released data or from previous empirical studies. The only free parameter, $\lambda-$ the arrival probability of an LBO - is backed out from observed bond prices and the use of Lemma 3. It has been reported that the total settlement to buy out the put options was about $\$ 98$ million for options on face value of $\$ 550$ million. News reports also suggested that one large insurance company - holding almost a fifth of the putable debt - had been paid 5 times per dollar as smaller bondholders for surrendering their options. ${ }^{9}$ Reports of unequal payments to different bondholders lead us to believe that the parties concerned were considering the relative threatening powers of the different bondholders in their evaluation of the settlement. The calibration exercise is as follows:

- Parameters of Vasicek Process (estimated in Chan, Karolyi, Longstaff and Sanders (1992)):

$$
\begin{aligned}
\alpha & =.18 \quad \text { (Vasicek process slope parameter) } \\
\gamma & =.085 \quad \text { (Vasicek process mean reversion parameter) } \\
\sigma_{r} & =.02 \quad \text { (Vasicek process volatility parameter) } \\
r & =.058 \quad \text { (Federal Funds Rate, November 1995) }
\end{aligned}
$$

- Bankruptcy Parameters (Empirical Research):

$$
\begin{array}{rll}
\phi & =.03 \quad \text { (Proportional costs of bankruptcy, Weiss 1990) } \\
\alpha_{B} & =.70 \quad \text { (Recovery on bank loans, Moody's 1997) } \\
\alpha_{D} & =.33 \quad \text { (Recovery on junior debt, Moody's 1997) } \\
\alpha_{E} & =.25 \quad \text { (Fraction of Equity Value of Reorganized Company to shareholders, Weiss 1990) } \\
\beta & =2.75 \quad \text { (Proportional Increase in debt in an LBO Transaction, Warga and Welch 1993) }
\end{array}
$$

- Parameters of Kmart's Stock Return Process (Based on Publicly Available Market Data from Bloomberg Financial Markets.)

$$
\begin{aligned}
\sigma_{V} & =.4 \quad \text { (Asset Volatility Parameter) } \\
\rho & =.14 \quad \text { (Correlation of Asset Value with Interest Rates) }
\end{aligned}
$$

\footnotetext{
9 Bloomberg Financial Markets, November 15 1995, and "Kmart Seen Offering Lump Payment to Remove Put Option," and "Kmart Shares Soar on Settlement with Debtholders," December 21 1995. The CFO at Kmart, Mr. Martin E. Welch III informed us that there was indeed one large bondholder holding about $\$ 100$ million of securities. The remainder of the debt was held about equally by 20 institutional lenders. He also said that if Kmart accelerated payments on more than $\$ 110$ million of the putable debt, then all its bank debt would also be put and hence force the Company into filing for Chapter 11 . This determines the trigger level of putable debt, $\mathcal{T}$.
} 
The average historical volatility of Kmart's stock return in the 1994-1997 period is about 0.4 (Figure 2). The average implied volatility on one month put options on Kmart's stock is higher, at about 0.49. Because the latter measure is subject to the usual specification errors we choose the actual volatility. We use this same volatility parameter for the asset return process. $\rho$ is the correlation in the same period between monthly returns on Kmart's stock and 30-day Treasury Bills.

- Balance Sheet Items (Book Value as listed in Kmart's 1995 Annual Report):

$$
\begin{aligned}
A_{0} & =\$ 15.3 b \quad(\text { Total Assets }) \\
B & =\$ 5.1 b \quad \text { (Senior Debt }) \\
D^{N} & =\$ 4.3 b \quad \text { (Junior Non-Putable Debt) } \\
D^{1} & =\$ .1 b \quad \text { (Putable Debt Held by One Large Bondholder) } \\
D & =\$ .45 b \quad \text { (Putable Debt Held by Small Bondholders }) \\
E & =\$ 6.03 b \quad \text { (Shareholder Equity) }
\end{aligned}
$$

- Covenant On Senior Debt (Footnote 9): The firm can accelerate payment on no more that $\$ .11$ b of junior putable bonds without triggering bankruptcy proceedings.

$$
\begin{aligned}
& \mathcal{T}=\$ .11 b \quad \text { (Trigger Level of Putable Debt) } \\
& N=20 \quad \text { (Number of Small Putable Bondholders) }
\end{aligned}
$$

- Market Value of the Firm (Historical stock and bond prices are from Bloomberg Financial Markets):

$$
\begin{aligned}
V_{E} & =3.46 b \quad 486,511 \text { Shares Outstanding at } \$ 7.125 \text { per share } \\
V_{B} & =\$ 5.61 \quad \text { Senior } 9 \% \text { Coupon Debt valued at about } \$ 1.10 \text { per dollar. }^{10} \\
V_{D} & =\$ 4.85 b \quad \text { Junior } 8 \frac{1}{2} \text { Debt valued at about } \$ .89 \text { per dollar } \\
\pi_{12} & =\$ .4 \quad \text { (Implied } 12-\text { Year Probability of Defaults })
\end{aligned}
$$

The average stock price of Kmart in December 1995 - the month of negotiations - was $\$ 7.125$ (Figure 2, top left). The calculation of the Implied 12-Year Probability of Default (under the risk-neutral measure) is as follows: The average maturity of debt outstanding was about 12 years. Most of the bonds carried a coupon of 7-11\%. As seen in the top right panel of Figure 2, the spread on Kmart debt increased to about 500 basis points. Market data reveals that Kmart's $8 \frac{1}{2}$ bonds traded at about 89 cents to the dollar. Using (4), and the parameters above for the Vasicek process at a short-term rate of $5.8 \%$ (the Federal Funds rate at the time of the crisis) imply that a 12-year discount bond would be valued at $P(.058,12)=.418$ cents per dollar. Typically, the recovery on junior debt in bankruptcy is $\alpha_{D}=.33$ (Moody's (1997)). Using the 
formula $P_{D}=P(.055,12) f_{D}\left[1+\pi_{12}\left(\alpha_{D}-1\right)\right]$ then implies $\pi_{12}=.4{ }^{11}$ Using the pricing formula for $9 \%$ senior coupon debt and a higher recovery $\alpha_{B}$, implies that senior debt would trade at about $\$ 1.1$ cents per dollar. The sum of the market values of the liabilities equals $\$ 13.27$ billion. The book value of assets is listed as $\$ 16.64$ b in Kmart's 1995 Annual Report.

- Values in an Immediate Reorganization: ${ }^{12}$ We assume that the level of debts on the books of the company shown above equal principal and accrued interest. Therefore,

$$
\begin{aligned}
& B_{\tau_{P} F}=\min \{(1-.03) \cdot 13.27,5.1\}=5.1 \quad \text { (Recovery on Senior Debt) } \\
& D_{\tau_{P} F}=\min \{(1-.03) \cdot 13.27-5.1-4.85\}=4.85 \quad \text { (Recovery on Junior Debt) } \\
& E_{\tau_{P} F}=(1-.03) 13.27-5.1-4.85=2.93 \quad \text { (Shareholders Equity Value) }
\end{aligned}
$$

- Implications of Model and the size of the 'Pie': The model implies that the default boundaries are

$$
\begin{aligned}
\nu & =17.53 \quad(\text { Default Boundary Prior to LBO as in }(7)) \\
\nu^{L} & =42.83
\end{aligned}
$$

Since $P(.055,12)$ equals $.418, \nu_{t}=7.32$ and $\nu_{t}^{L}=17.9$. To match the default probability of $\pi_{12}=.38$, with the market values of junior and the above default boundaries, the implied value of the LBO arrival parameter is $\lambda=.02$. However, because the current market value of the assets is very low, with a high probability the value of the assets at the time of the LBO offer arrival will be below $\nu_{t}^{L}$, the higher default boundary in the event the LBO is consummated. The model implies that the probability of a Type-C default (see Figure 3 ) is only about .04\%. Using (19) these boundaries imply that the expected discounted bankruptcy costs equal $\mathcal{B}^{P} P(0,12)=\$ .1 b$. Finally, using $(28), \bar{v}$, the 'pie' to be shared between the putable bondholders and the firm is $\$ 3.71 \mathrm{~b}$.

Using Lemma 8 with the above parameter values, it is estimated that the strategic value per dollar of option at the time of bargaining was about $\$ .48$ per dollar for the large bondholder, and about $\$ .43$ per dollar for the small bondholders, for an aggregate payment of about $\$ 241$ million. Some reports have suggested that Kmart made a total payment of about $\$ 98$ million for the removal of the options. Also, the model suggests that the strategic value for the large bondholder was larger than that of the smaller bondholders, but the difference is not as large as rumored in the media (opening paragraph of this section). ${ }^{13}$ The model also suggests that if there was a single bondholder owning all the debt, the payout for the firm would have been $\$ 70$ million lower! Similarly, have a trigger of about $\$ 220$ million instead of $\$ 110$ million, would have saved the firm almost $\$ 60$ million at the time of settlement.

\footnotetext{
${ }^{11}$ This is an approximation. To be more exact we should find 24 prices of bonds with different coupons, and use the bondpricing formula to simultaneously infer the probabilities of default at each coupon date.

${ }^{12}$ See Figure 4 for the definitions of the recoveries.

${ }^{13}$ If the amounts held by the large and small bondholders were reversed, that is the large bondholder held $\$ 450$ million of putable bonds, then the model implies that the strategic value of his option would indeed be 5 times larger.
} 
Readers might suppose that the strategic values calculated are implausibly high. One reason that the strategic value per dollar calculated is enormous, is because the exercise of more than $\$ 110$ million of putable bonds can reduce the claims of equity holders by about $\$ 800 \mathrm{~m}$. As another conceptual experiment, suppose all the firms junior debt was putable. Keeping the same proportional trigger amount of 20 percent of the face value of the putable debt, or $\$ 1$ billion, we recalculate that the strategic value of the large bondholder is about $16.8 \mathrm{c}$ per dollar of putable debt, and that of the small bondholder is about $16 \mathrm{c}$ per dollar.

\section{Pricing Options Prior to Crisis}

In this section we shall price two different kinds of Poison Put Bonds at the time of issuance of these bonds. We shall call the bonds 'Ordinary' Poison Puts, when holders can put their bonds back to the issuer at par in the event of a leveraged restructuring and subsequent downgrading to speculative grade (any specific rating category). ${ }^{14}$ We shall call the bonds 'Super' Poison Puts, when the holders can put the bonds if the credit rating of the bonds hits speculative grade, irrespective of the reason for the downgrade (see the comments in Section about the evolution of such bonds). We shall assume that the rating of the bonds are solely determined by their probabilities of default. Because the value of the firm's assets follows a continuous process, for every time-horizon there exists a lower bound for the value of the firm's assets hits in situation $K$, the rating turns from investment to speculative grade. It is evident that for a given probability of default at any horizon $\underline{V}_{L, t} \geq \underline{V}_{P, t} \geq \underline{V}_{U, t}$ because the default boundary is lowest for the case $K=U$, and highest for $K=L$; for the case $K=P$, the higher default boundary obtains when an LBO is successfully consummated, and since this is in independent event with probability less than one, $\underline{V}_{P}$, lies between the other two.

Assumption 8 The speculative grade boundary in situation $K$, for $K=P, L, U$, is given by $\underline{V}_{K, t}=$ $\underline{V}_{K} P\left(r_{t}, T\right)$, where $\underline{v}_{K}$ is a constant that will be substituted into (9) to match the default scale $\pi_{S}(T)$ by Moody's Investor Service, as shown in Table 1. Corresponding to the normalization of asset value in Section 3, we define $\underline{v}_{K, t}=\underline{v}_{K} P\left(r_{t}, T\right)=\ln \left(\frac{\underline{V}_{K, t}}{\nu_{t}}\right)$.

The super poison puts are exercisable (a) Prior to the LBO the asset value drifts down to the default boundary, (b) At the time of the LBO, the firm's credit rating (default probability) jumps down due to a rise in the default boundary (c) After a successful LBO, the firm's rating is above speculative grade, but subsequently the asset value drift down to the higher default boundary, and (d) After an unsuccessful LBO attempt, the firm's rating is above speculative grade, but subsequently the asset value drift down. Let $\pi_{S}(T)$ be an exogenously given function that gives the probability of default for a bond of maturity $T$, at which the rating turns from investment to speculative grade.

\footnotetext{
${ }^{14}$ While several bonds become putable when the rating hits speculative grade, the rating boundary specified differs widely across bonds. The analysis is this section is valid for any specific rating by substituting probabilities of default at different horizons for the speculative grade category by the corresponding probabilities of default for the rating specified in the contract of the bond.
} 
Prior to an LBO, the firm's rating turns speculative grade when its normalized value $q_{t}$ hits $\underline{v}_{K}$. The option pays off at the first time the value hits a payoff boundary. Since the rating boundary increases at the riskless rate (same as the default boundary), analogous logic to that used in Lemma 1 and the spatial homogeneity of Brownian Motion implies that conditional on $q_{0}$, the density of the time to hit speculative grade is

$$
\pi^{r^{\prime}}\left(m_{0}, 0, t\right)=\pi^{\prime}\left(m_{0}-\underline{v}_{P}, 0, t\right)
$$

where $\pi^{\prime}\left(m_{0}, 0, t\right)$ is given by (10). Similarly, the transition density on the normalized space, conditional on the firm's value always remaining above the speculative grade boundary is

$$
p^{r}\left(m_{0}, y, 0, t\right)=p^{a}\left(m_{0}-\underline{v}_{P}, y-\underline{v}, 0, t\right)
$$

where $p^{a}\left(q_{0}, y, t\right)$ is given by (11).

Result 3 (Super Poison Puts) Let $P_{0}(f)$ be the value at the time 0 of issuance of a situation-dependent security, $f$, that pays the value $f^{K}\left(V_{\tau_{P}}\right)$, at the time of exercise of the super poison put options $\tau_{P}$, if the situation is $K$, and the exercise boundaries are defined in Assumption 8. Then, its value is the sum of four parts. Each part constitutes the value of the option in one of four mutually exclusive events $E, F, F, H$.

$$
\begin{aligned}
& P_{0}^{E}(f)=P\left(r_{0}, T\right) \cdot \int_{0}^{T} \pi^{r^{\prime}}\left(q_{0}, 0, s\right) f^{P}\left(\underline{V}_{P, s}\right) e^{-\lambda s} d s \\
& P_{0}^{F}(f)=P\left(r_{0}, T\right) \cdot \int_{0}^{T} \int_{\underline{v}_{P}}^{l} \lambda e^{-\lambda s} p^{r}\left(m_{0}, y, 0, s\right)\left(\int_{s}^{T} \pi^{r^{\prime}}\left(y+\underline{v}_{P}-\underline{v}_{U}, s, t\right) f^{U}\left(\underline{V}_{U, s}\right) d t\right) d y d s,(49) \\
& P_{0}^{G}(f)=P\left(r_{0}, T\right) \cdot \int_{0}^{T} \int_{l}^{\underline{v}_{L}} \lambda e^{-\lambda s} p^{r}\left(m_{0}, y, 0, s\right) f^{L}\left(e^{y} \cdot \nu \cdot P\left(r_{t}, T\right)\right) d y d s, \quad \text { and } \\
& P_{0}^{H}(f)=P\left(r_{0}, T\right) \cdot \int_{0}^{T} \int_{\underline{v}_{L}}^{\infty} \lambda e^{-\lambda s} p^{r}\left(m_{0}, y, 0, s\right)\left(\int_{s}^{T} \pi^{r^{\prime}}\left(y-\left(\underline{v}_{U}-\underline{v}_{P}\right), s, t\right) f^{L}\left(\underline{V}_{L}\right) d t\right) d y d s(.5)
\end{aligned}
$$

Where $l$ was defined in Lemma $3, \pi^{r^{\prime}}\left(q_{0}, 0, t\right)$ is defined in (46) and $p^{r}\left(q_{0}, y . s, t\right)$ is defined in $(47)$.

The proof is in the appendix. Again for exposition we display the payoffs under the four events in Figure 8.

Corollary 4 Suppose Condition 1 holds at each boundary $V_{K \tau_{P}}$, for $K=P, L, U$. Let $P_{0}(1)$ be the value of a security that pays $P\left(r_{\tau_{P}, T}\right)$ at $\tau_{P}$.

$$
\begin{aligned}
P_{0}\left(\bar{v}_{\tau_{P}}^{K}\right) & =P_{0}(\underline{v})-P_{0}(\mathcal{B})-B P_{0}\left(P_{B}\right) \\
P_{0}\left(P_{B}\right) & \left.=P_{0}(1) f_{B}+f_{B} P_{0}(\pi(\cdot, \cdot))\left(\alpha_{B}-1\right)\right], \\
E_{0}\left[E_{\tau_{P} F}\right] & =(1-\phi) P_{0}(\underline{v})-P_{0}(1) B f_{B}-P_{0}(1) D f_{D} \\
D_{0}\left[D_{\tau_{P} F}\right] & =P_{0}(1) D f_{D}
\end{aligned}
$$


where $\bar{v}_{\tau_{P}}^{K}$ is defined in (28), $\underline{v}$ takes the values $\underline{v}_{K}$ is situation $K$ as given in Assumption $8, \mathcal{B}$ takes the values $\mathcal{B}^{K}$ given in (19), (20), (21), $P_{B}(\cdot, \cdot)$ takes the values $P_{B}^{K}(\cdot, \cdot)$ as provided in Lemmas 2 and 3, $P_{0}(\cdot)$ is the operator defined in Lemma 3, and $E_{0}(\cdot, \cdot)$ denotes the expectation at time 0 under the risk-neutral measure $Q$.

Proof. The value of the firm at $\tau_{P}$ equals $\underline{V}_{K, \tau_{P}}$. By Assumption 8, this equals $\underline{v}_{K} P\left(r_{\tau_{P}}, T\right)$, which has a time $T$ value of $\underline{v}_{K}$. Therefore $P_{0}\left(V_{\tau_{P}}\right)=P_{0}(\underline{v})$, where $P_{0}(\cdot)$ is the operator defined in Lemma 3. Now using the definition of $\bar{v}_{\tau_{P}}^{K}$ in (28) implies (52). The proof for the other variables results from a similar application of the $P_{0}(\cdot)$ operator.

Corollary 4 can be used to find formulas for the intrinsic and strategic values of the put options at the time of issuance. The strategic value of the options depends on the ownership structure of the options at the time of the put; to price the strategic value at the time of the crisis, we shall assume that all agents believe that the ownership structure of the options will not change upto the maturity of the debt. Given the ownership structure, the strategic value of each player at the time of bargaining will provide the boundary conditions for the value of the option, when the asset value hits the triggering boundary $\underline{V}_{K, t}$ in situation $K$ at time $t$.

Assumption 9 All agents believe that the ownership structure of the options will not change upto the maturity of the debt.

For example, for the case of $N$ equally sized putable bondholders, using (32) and (44)

$$
\begin{aligned}
& P_{0}(I V)=f_{D}\left(1-\alpha_{D}\right) P_{0}\left(\pi^{K}(\cdot, \cdot)\right), \quad \text { and } \\
& P_{0}(S V)=\left(1-\alpha^{N}\right)\left[\frac{P_{0}(\bar{v})-P_{0}\left(E_{\tau_{P} F}\right)}{D}-P_{0}(1) f_{D}\right]+P_{0}(I V)
\end{aligned}
$$

In the case when there is one large holder holding $D^{1}$ of putable debt, and $N$ equally sized holders owning $D$ of the debt, the equations in Lemma 8 determine the boundary conditions for the value of the firm and the bondholders. Then Corollary 4 determines the value of the relevant variables at the time of issuance, as illustrated in 57 .

When Condition 1 is not satisfied, then Corollary 4 cannot be used directly. In that situation, the payoffs in an bankruptcy will have to substituted at the boundaries where the condition fails.

Result 4 (Ordinary Poison Puts) Let $P_{0}^{o}(f)$ be the value at the time 0 of issuance of a situation-dependent security, $f$, that pays the value $f^{L}\left(V_{\tau_{P}}\right) P\left(r_{\tau_{P}, T}\right)$, at the time of exercise of the ordinary poison put options $\tau_{P}$, if the situation is $L$, and the exercise boundaries are defined in Assumption 8. Then

$$
P_{0}^{o}(f)=P\left(r_{0}, T\right) \cdot \int_{0}^{T} \int_{l}^{\underline{v}_{L}} \lambda e^{-\lambda s} p^{a}\left(q_{0}, \frac{y}{\nu}, 0, s\right) f^{L}(y) d y d s
$$


Proof. The firm's rating turns from investment to speculative grade at the time of LBO if its normalized value lies in $\left(l, \underline{v}_{L}\right)$. Using the density function of the LBO arrival and integrating implies (58).

We note that the formula for valuing the ordinary poison put closely resembles the formula for $P_{0}(G)$ of the super poison put in Lemma 3. The only difference is that the super poison put pays off at the first time the rating hits speculative grade, while the ordinary put does not. Ofcourse, the option does not pay off if the firm defualts prior to the LBO arrival. Therefore, we use the transition density function $p^{a}\left(q_{0}, y, 0, t\right)$ for the ordinary put valuation and the $p^{r}\left(q_{0}, y, 0, t\right)$ transition density for the super poison put valuation. Again, the speculative grade rating boundary in the formulation can be substituted by any specific rating category.

\section{Example 5 (Market Value of Assets, Credit Rating and the Value of Options)}

In this example we find the strategic and intrinsic values of putable bonds for firms with different asset values and hence different credit ratings. We use Results 3 and 4 to price the Super and Ordinary Poison Puts respectively. The options are priced at issuance, with a maturity of 20 years. The various parameter assumptions are as follows: Parameters for the Vasicek process and those determining payoffs of different players in bankruptcy are the same as in Section 8. It is assumed that $\rho=0$ (zero correlation between asset returns and the short-term rate). The asset volatility parameter is $\sigma_{V}=.3$, and the LBO exponential distribution arrival parameter is $\lambda=.03$. The face values of debt issued are $B=5.1, D^{N}=4.3$, and $D=.55$; (6) and (7) imply that $\nu=18.32$, and 44.76. Using Lemmas 2 and 3 , we estimate that the rating bounds for the assets are $\underline{v}_{P}=48.99, \underline{v}_{L}=45.2$, and $\underline{v}_{L}=112.50$. (56) is used to price the intrinsic value of the super poison put. Using Result 4 an analogous formula is used to price the ordinary Poison Put. It is assumed that the trigger value of putable debt is set by covenants at .1, and the bonds are held by infinitesimal bondholders. Therefore, the limiting value of the ratio $M^{c} / N+1=\mathcal{T} / D$ is used in (57) in the calculation of strategic value.

Recall that the firm's rating are lowered into the speculative grade range in situation $S$ at time $t$ if the value of its assets falls to $\underline{v}_{S} P\left(r_{t}, T\right)$. The cumulative probabilities of default over horizons of $1,2,5,10$, and 20 years are $.010, .037, .12, .22, .37$ when the value of the assets hits $\underline{V}_{P, t}$ prior to an LBO arrival. After an LBO arrival, the implied default rates are $.007, .035, .11, .23, .38$ respectively for the five time horizons. Moody's usually rates firms with a 20 -year cumulative default rate of .38 or more speculative grade (Table 1). ${ }^{15}$

Strategic and intrinsic values are shown in Table 2. The table shows that the strategic and intrinsic values are each decreasing in the value of the firm. This is because the probability of a payout increases as the value of the firm is lowered towards it downgrade boundary. Using Lemma 3 we estimate the 20-year

\footnotetext{
${ }^{15}$ Jones, Mason and Rosenfeld (1994) (among other authors) have cited the difficulty of a model with a continuous asset process in generating an empirically plausible probability of default at short horizons. Zhou (1997) resolves the problem with a discontinuous jump process; we generate a higher probability of default, prior to an LBO arrival, with a jump in the default boundary, which occurs upon the completion of an LBO. Since we have modeled the arrival of only one LBO, we cannot match the same 1-year probability of default after the LBO arrival.
} 
default probabilities for each of the asset values displayed. The probabilities are usually associated with Moody's rating as shown in the third column. The intrinsic values of the ordinary Poison Puts are extremely small, between .001 and .006 for firms with ratings comparable Aaa to Baa2. The strategic values range between .02 and .19 for these rating categories. The strategic values of the Super Poison puts are about 12-17 times larger than their intrinsic values. Also notably, the strategic values of the options can be larger than 1 , for firms with ratings close to the speculative grade boundary. In these cases the value of the options will increase the face value of the debt.

\section{Example 6 (Correlation Between Asset Value and Short-Term Rates and the Value of Options).}

The same set of parameters are used for the last example. However, the asset value for all cases considered is 45 . The correlation coefficient $\rho$ is varied between -.3 and .3 . For each case, the rating boundaries for the normalized asset process $\underline{v}_{K}$, for $K=P, L, U$ are recalculated for each example and are shown in columns 3-5 of Table 3. These levels are calculated using Lemma 3 to match the 20-year default probability of Moody's Ba rated bonds. It can be checked that Condition 1 is satisfied at each of the boundaries for each case considered. The rating boundaries are increasing in the correlation coefficient, since the asset process is effectively more 'volatile'. Therefore the probability of default is hit when the firm has a higher asset value. Because of the higher asset values at the times the options become exercisable, the intrinsic and strategic values of the options are greater.

\section{Conclusion and Extensions}

Putable bonds give the bondholders threatening power to force the company into a reorganization in times of low liquidity. We have used recent results in bargaining theory to provide strategic values of putable bonds. It is shown that these bondholders can extract more than their intrinsic values from the company. The strategic values of these bondholders depend crucially on the effective liquidity-to-putable debt ratio of the firm. Even when the number of bondholders increases to infinity (a reasonable approximation for publicly issued bonds), the two values will not coincide for an effective liquidity-to-putable debt ratio less than one. A calibration exercise suggests that a large bondholder had a significantly higher strategic value in a poison put induced crisis affecting Kmart Corp. last year. While previous research has shown that including a put provision into bonds can reduce the yields for issuers, there seems to be a possibility of a large cost of including such covenants. In Kmart's case, the crisis would have been avoided (the bondholders would have negligible threatening power) if the company had not entered into some very restrictive covenants on the use of cash with their banks. While it is very clear why the banks wanted such a covenant - they did not want an effective violation of their seniority and hence be left as the last claimants in case of a large deterioration in the firm's credit quality - our model suggests that the company could have saved itself of a costly payout by either (a) issuing all the putable debt to one borrower, or (b) having a looser covenant on option buyback. Prior to the crisis, the model suggested is general enough to price different variations on 
the poison puts. In light of the vast heterogeneity in the contingencies that might trigger the put (Section 2), a careful analysis of the contract is essential for a useful pricing exercise.

The paper has focused on the negotiation that arises between a borrower and lenders as a result of the borrower's violation of a particular covenant - the value of its assets hitting a pre-specified lower bound. The negotiations are successful if the combined value of the parties is higher in continuation than in an immediate costly reorganization. The bargaining solution exhibits differential strategic value for large and small lenders and non-vanishing strategic values for lenders even for infinitesimal lenders. One important extension of this analysis is to analyze the recontracting possibilities that arise upon the violation of other covenants that are set in bond contracts to mitigate the conflicts of interest between shareholders and bondholders (see for example, Smith and Warner 1979). The can also be extended to the bank loan and private placement markets, in which it is also typical for lenders to impose covenants on the firm's debt and for the prevalance of large players of different sizes (see for example, Carey, Prowse, Rea and Udell 1993). A strategic value approach might partly explain why the nature of covenants varies across the three types of loans. Because the solution proposed holds only under symmetric information between the parties involved, its usefulness would be limited to the analysis when the contracts being analyzed have this property.

\section{Appendix.}

\section{Proof of Lemma 3.}

First, suppose that the LBO offer arrives at some time $s \in[0, T]$ (the probability of this is $f(s \mid \lambda)=\lambda \exp (-\lambda s))$. Then, there are three mutually exclusive possibilities (purely for exposition, these are illustrated in Figure 3). We shall use the Chapman-Kolmogorov property of Markov processes, and the independence of the LBO arrival process from interest rate and asset value shocks, to compute the probability of default of the firm before maturity. Let $\pi^{P}\left(q_{t}, \nu_{t}^{L}, t, T\right)$ be the risk-neutral probability of default; it can be written as $\pi^{P}\left(q_{t}, \nu_{t}^{L}, t, T\right)=\pi^{A}\left(q_{t}, \nu_{t}^{L}, t, T\right)+\pi^{B}\left(q_{t}, \nu_{t}^{L}, t, T\right)+\pi^{C}\left(q_{t}, \nu_{t}^{L}, t, T\right)+\pi^{D}\left(q_{t}, \nu_{t}^{L}, t, T\right)$ where $A, B, C, D$ are mutually exclusive events to be described below. A Type A default occurs when the asset process hits the default barrier before $s$. Paths of Type B have $\nu_{s} \leq V_{s} \leq \nu_{s}^{L}$, or equivalently $0 \leq q_{s} \leq \ln (l)$, where $l=\frac{\alpha_{B} B+\beta \alpha_{D} D}{\alpha_{B} B+\alpha_{D} D}$. Because the value of the firm is lower than the post-LBO default boundary, the LBO is not consummated, the default boundary is not increased, and the firm subsequently defaults when $q_{t}$ hits 0 . Paths of Type C, lead to a successful LBO transaction at $s$ and a subsequent default when $q_{t}$ hits $\ln (l)$ prior to $T$. The only remaining possibility (event $\mathrm{D}$ ) is that the LBO offer does not arrive prior to the maturity of debt, and the probability of the firm defaulting is simply the probability of defaulting prior to $T$ without any change in the default barrier. given by (18). Now using the Feynman-Kac solution of the bond price as in Lemma 2 yields (14).

\section{Proof of Lemma 6.}


The amount to be shared by equity holders and putable bondholders if a settlement is successfully negotiated is given by $\bar{v}_{\tau_{P}}^{K}=V_{t}-\mathcal{B}^{K} P\left(r_{\tau_{P}}, T\right)-B P_{B}^{K}$, where $\mathcal{B}_{T}^{K}$ is provided in Lemma 4 . For convenience, the arguments of the price and bankruptcy cost functions have been omitted. The amount to be shared by these players in an immediate reorganization is given by $E_{\tau_{P} F}+D_{\tau_{P} F}=(1-\Phi) V_{t}-B_{\tau_{P} F}$, which equals

$$
(1-\Phi) V_{t}-B f_{B} P\left(r_{\tau_{P}}, T\right)
$$

under Condition 1 (senior bank debt is paid in full if the junior debt has non-zero recovery). For situations $L$ and $U$ the proof is straightforward: Using Lemma 2, the value of resources in continuation equal

$$
V_{t}-\mathcal{B}_{t}^{K} P\left(r_{\tau_{P}}, T\right)-B f_{B} P\left(r_{\tau_{P}}, T\right)\left[1+\pi\left(q_{t}, t, T\right)\left(\alpha_{B}-1\right)\right]
$$

where $q_{t}=\frac{V_{t}}{\nu_{t}^{L}}$ for $K=L$, and $q_{t}=\frac{V_{t}}{\nu_{t}}$ for $K=U$. Because future expected bankruptcy costs in situation $K$ are simply equal to $\Phi$ times the default boundary, and the firm is currently solvent $\left(V_{t}>\nu_{t}\right.$ for $K=U$ or $V_{t}>\nu_{t}^{L}$ for $K=L$ ) its current bankruptcy costs (if it fails immediatley) exceed future expected bankrputcy costs - or $\Phi V_{\tau_{P} F}>\mathcal{B}_{\tau_{P}}^{K}$. Condition 1 implies that the value of bank debt (in continuation) is lower than $B f_{B} P\left(r_{\tau_{P}}, T\right)$, the amount to be paid to bankholders immediately. Therefore, the quantity in (60) exceeds the quantity in (59).

When $K=P$ - when the LBO offer has not yet arrived - and when $V_{\tau_{P}} \geq \nu_{\tau_{P}}^{L}$, the same logic as for the above cases applies. The case left to consider is when $\nu_{\tau_{P}}^{L}>V_{\tau_{P}}>\nu_{\tau_{P}}$. Under the risk-neutral measure $Q$, no-arbitrage implies that the value of the firm's assets must satisfy

$$
V_{\tau_{P}}=\left[\pi^{P}\left(\frac{V_{\tau_{P}}}{\nu_{\tau_{P}}}, \tau_{P}, T\right)-\pi^{C}\left(\frac{V_{\tau_{P}}}{\nu_{\tau_{P}}}, \tau_{P}, T\right)\right] \nu_{t}+\pi^{C}\left(\frac{V_{t}}{\nu_{t}}, t, T\right) \nu_{t}^{L}+P\left(r_{\tau_{P}}, T\right) E_{Q}\left[V_{T} \mid \text { Firm is solvent }\right]
$$

Since the last term is positive,

$$
V_{\tau_{P}} \geq\left[\pi^{P}\left(\frac{V_{\tau_{P}}}{\nu_{\tau_{P}}}, \tau_{P}, T\right)-\pi^{C}\left(\frac{V_{\tau_{P}}}{\nu_{\tau_{P}}}, \tau_{P}, T\right)\right] \nu_{t}+\pi^{C}\left(\frac{V_{t}}{\nu_{t}}, t, T\right) \nu_{t}^{L}
$$

Since bankruptcy costs are proportional to the value of the firm's assets at bankruptcy, current bankruptcy costs are larger than expected future bankruptcy costs, and the same steps as for the other cases apply.

\section{Proof of Result 1.}

Following Hart and Mas-Colell (1996) we define the function $V_{\tau_{P}}^{K}(\cdot)$, that assigns a subset $V(S)_{\tau_{P}}^{K}$ of $\mathcal{R}^{S}$ to every coalition $S \subset I$. When all players are risk-neutral then the set $V_{\tau_{P}}^{K}(S)=\left\{c \in \mathcal{R}^{S}\right.$ : $\left.\sum_{i \in S} c^{i} \leq v(S)\right\}$, where $v_{\tau_{P}}^{K}(S)$ is the sum of the resources available to the players in $S$. There are three requirements for the set $V_{\tau_{P}}^{K}(S)$ : 
(A.1) For each coalition $S$, the set $V_{\tau_{P}}^{K}(\cdot)$ is closed, convex and comprehensive (i.e., $V_{\tau_{P}}^{K}(\cdot)-\mathcal{R}_{+}^{S} \subset$ $\left.V_{\tau_{P}}^{K}(\cdot)\right)$. Moreover, $0 \in V_{\tau_{P}}^{K}(\cdot)$ and $V_{\tau_{P}}^{K}(\cdot) \cap \mathcal{R}_{+}^{S}$ is bounded.

(A.2) For each coalition $S$, the boundary of $V_{\tau_{P}}^{K}(\cdot)$ is smooth and nonlevel (i.e. the outward normal vector at any point of the boundary is positive in all coordinates).

(A.3) Monotonicity: $V_{\tau_{P}}^{K}(\cdot) \times\left\{0^{T \backslash S}\right\} \subset T$ (i.e. if one completes a vector in $V_{\tau_{P}}^{K}(\cdot)$ with 0 's for the coordinates in $T \backslash S$, then one obtains a vector in $V_{\tau_{P}}^{K}(\cdot)(T)$.

For the set $V_{\tau_{P}}^{K}(S)=\left\{c \in \mathcal{R}^{S}: \sum_{i \in S} c^{i} \leq v_{\tau_{P}}^{K}(S)\right\},(A .1)$ and (A.2) trivially hold. For (A.3), it is required that $v_{\tau_{P}}^{K}(S) \leq v_{\tau_{P}}^{K}(T)$ whenever $S \subset T$. It is evident from the defintion of $v_{\tau_{P}}^{K}$ that the only nonmonotinicites can arise when $D_{P}=\mathcal{T}$. By Lemma $6, \bar{v}_{\tau_{P}}^{K}>E_{\tau_{P} F}+D_{\tau_{P} F}$, and therefore $v_{\tau_{P}}^{K}\left(E \bigcup D_{C}\right)$ increases as $D_{C}$ crosses the threshold $(D-\mathcal{T})$, the smallest level of cooperating putable debt needed to avoid an immediate reorganization. If Condition 1 holds, then $D_{\tau_{P} F}=D f_{B} P\left(r_{\tau_{P}}, T\right)$, and therefore, $v_{\tau_{P}}^{K}\left(D_{P}\right)$ increases as $D_{P}$ crosses the trigger level $\mathcal{T} .^{16}$

\section{Proof of Lemma 7.}

We will show that the marginal value of player $i$ in any coaliton exceeds $D_{i} f_{B} P\left(r_{\tau_{P}}, T\right)$. Under Condition 1, (26) and (27) imply that the value of any pure bondholder coaliton with debt $D_{S}$ equals $D_{S} f_{D} P\left(r_{\tau_{P}}, T\right)$; therefore, the marginal contribution of a bondholder with debt $D_{i}$ to all such coalitons is $D_{i} f_{B} P\left(r_{\tau_{P}}, T\right)$. Now consider the marginal value of the bondholder in coalitions that include the firm. Let $D_{C}$ be the total value of debt of cooperating bondholders that includes $D_{i}$. If $D_{C}-D_{i} \geq(D-\mathcal{T})$, then with or without the cooperatiaon of $i$, the firm need not file for a reorganization immediately; using (29), the marginal value of bondholder $i$ equals $D_{i} f_{B} P\left(r_{\tau_{P}}, T\right)$. The last case is when $D_{C}-D_{i}<(D-\mathcal{T})$, but $D_{C} \geq(D-\mathcal{T})$. In this case, bondholder $i$ is pivotal; using (29) and (30), the marginal value of player $i$ equals

$$
\begin{aligned}
v_{\tau_{P}}^{K}\left[E \bigcup D_{C}\right]-v_{\tau_{P}}^{K}\left[E \bigcup\left(D_{C}-D_{i}\right)\right] & =\bar{v}_{\tau_{P}}^{K}-\left(D-D_{C}\right) f_{D} P\left(r_{\tau_{P}}, T\right)-\left[D_{\tau_{P} F} \frac{D_{C}-D_{i}}{D}+E_{\tau_{P} F}\right] \\
& =\bar{v}_{\tau_{P}}^{K}-D_{\tau_{P} F}-E_{\tau_{P} F}+D_{i} f_{D} P\left(r_{\tau_{P}}, T\right),
\end{aligned}
$$

and Lemma 6 implies that the last quantity exceeds $D_{i} f_{D} P\left(r_{\tau_{P}}, T\right)$.

\section{Proof of Lemma 8.}

Value of Firm:

\section{Coalitions without $D^{1}$ :}

$$
0 \leq m<M^{0} ; \quad v\left(\bigcup_{i=0}^{m} D_{i}\right)=\frac{m}{N} D f_{D} P\left(r_{\tau_{P}}, T\right)
$$

\footnotetext{
${ }^{16}$ If $D_{\tau_{P} F}<D f_{B} P\left(r_{\tau_{P}}, T\right)$, then $v(\mathcal{T}+\epsilon)=\frac{\mathcal{T}+\epsilon}{D} D_{\tau_{P} F}<\mathcal{T}=v(\mathcal{T})$ for a small $\epsilon>0$.
} 


$$
\begin{aligned}
& m \geq M^{0} ; \quad v\left(\bigcup_{i=0}^{m} D_{i}\right)=\frac{\frac{m}{N} D}{D+D^{1}} D_{\tau_{P} F} \\
& 0 \leq m \leq N-M^{1} ; \quad v\left(\bigcup_{i=0}^{m} D_{i} \bigcup E\right)=\frac{\frac{m}{N} D}{D+D^{1}} D_{\tau_{P} F}+E_{\tau_{P} F} \\
& m>N-M^{1} ; \quad v\left(\bigcup_{i=0}^{m} D_{i} \bigcup E\right)=\bar{v}_{\tau_{P}}-\left(D_{1}+\frac{N-m}{N} D\right) f_{D} P\left(r_{\tau_{P}}, T\right)
\end{aligned}
$$

The coalition has $m+1$ members and there are $\frac{N !}{(N-m) ! m !}$ such coalitions. Each of these has the same value, therefore $\gamma(N+2, m+2) \cdot \frac{N !}{(N-m) ! m !}=\frac{N-m+1}{(N+2)(N+1)}$.

Coalitions with $D^{1}$ :

$$
\begin{aligned}
0 \leq m<M^{1} ; & v\left(\bigcup_{i=0}^{m} D_{i} \bigcup D^{1}\right) & =\left(\frac{m}{N} D+D^{1}\right) f_{D} P\left(r_{\tau_{P}}, T\right) \\
m \geq M^{1} ; & v\left(\bigcup_{i=0}^{m} D_{i} \bigcup D^{1}\right) & =\frac{\frac{m}{N} D+D^{1}}{D+D^{1}} D_{\tau_{P} F} \\
0 \leq m \leq N-M^{0} ; & v\left(\bigcup_{i=0}^{m} D_{i} \bigcup E \bigcup D^{1}\right) & =\frac{\frac{m}{N} D+D^{1}}{D+D^{1}} D_{\tau_{P} F}+E_{\tau_{P} F} \\
m>N-M^{0} ; & v\left(\bigcup_{i=0}^{m} D_{i} \bigcup E \bigcup D^{1}\right) & =\bar{v}_{\tau_{P}}-\left(\frac{N-m}{N} D\right) f_{D} P\left(r_{\tau_{P}}, T\right)
\end{aligned}
$$

The coalition has $m+2$ members and there are $\frac{N !}{(N-m) ! m !}$ such coalitions. Each of these has the same value, therefore $\gamma(N+2, m+2) \cdot \frac{N !}{(N-m) ! m !}=\frac{m+1}{(N+2)(N+1)}$. Now substituting (61) - (68) into (31) provides the expression for the strategic value of the firm.

Value of the Large Bondholder:

Coalitions without $E$ :

$$
\begin{aligned}
0 \leq m<M^{0} ; & v\left(\bigcup_{i=0}^{m} D_{i}\right) & =\frac{m}{N} D f_{D} P\left(r_{\tau_{P}}, T\right) \\
m \geq M^{0} ; & v\left(\bigcup_{i=0}^{m} D_{i}\right) & =\frac{\frac{m}{N} D}{D+D^{1}} D_{\tau_{P} F} \\
0 \leq m<M^{1} ; & v\left(\bigcup_{i=0}^{m} D_{i} \bigcup D^{1}\right) & =\left(\frac{m}{N} D+D^{1}\right) f_{D} P\left(r_{\tau_{P}}, T\right) \\
m \geq M^{1} ; & v\left(\bigcup_{i=0}^{m} D_{i} \bigcup D^{1}\right) & =\frac{\frac{m}{N} D+D^{1}}{D+D^{1}} D_{\tau_{P} F}
\end{aligned}
$$

The coalition has $m+1$ members and there are $\frac{N !}{(N-m) ! m !}$ such coalitions. Each of these has the same value, therefore $\gamma(N+2, m+1) \cdot \frac{N !}{(N-m) ! m !}=\frac{N-m+1}{(N+2)(N+1)}$. 


\section{Coalitions with E:}

$$
\begin{aligned}
0 \leq m \leq N-M^{1} ; & v\left(\bigcup_{i=0}^{m} D_{i} \bigcup E\right) & =\frac{\frac{m}{N} D}{D+D^{1}} D_{\tau_{P} F}+E_{\tau_{P} F} \\
m>N-M^{1} ; & v\left(\bigcup_{i=0}^{m} D_{i} \bigcup E\right) & =\bar{v}_{\tau_{P}}-\left(\frac{N-m}{N} D+D^{1}\right) f_{D} P\left(r_{\tau_{P}}, T\right) \\
0 \leq m \leq N-M^{0} ; & v\left(\bigcup_{i=0}^{m} D_{i} \bigcup E \bigcup D^{1}\right) & =\frac{\frac{m}{N} D+D^{1}}{D+D^{1}} D_{\tau_{P} F}+E_{\tau_{P} F} \\
m>N-M^{0} ; & v\left(\bigcup_{i=0}^{m} D_{i} \bigcup E \bigcup D^{1}\right) & =\bar{v}_{\tau_{P}}-\left(\frac{N-m}{N} D\right) f_{D} P\left(r_{\tau_{P}}, T\right)
\end{aligned}
$$

The coalition has $m+2$ members and there are $\frac{N !}{(N-m) ! m !}$ such coalitions. Each of these has the same value, therefore $\gamma(N+2, m+2) \cdot \frac{N !}{(N-m) ! m !}=\frac{m+1}{(N+2)(N+1)}$. Now substituting (69)-(76) into (31) provides the expression for the strategic value of the large bondholder. Since the sum of the players values equal $\bar{v}_{\tau_{P}}$, the value of each of the smaller bondholders equals $\frac{\bar{v}_{\tau_{P}}-\phi^{E}-\phi^{D^{1}}}{N}$

\section{Proof of Result 3.}

The option pays off when the firm's credit rating hits speculative grade - which by Assumption 8 sets lower bounds on the value of the firm's assets in situation $K, K=P, L, U$. The security therefore pays the value $f^{K}\left(\underline{V}_{\tau_{P}}\right)$ at the time of exercise of the super poison put option, $\tau_{P}$. Let $E$ be the event that the firm's rating hits speculative grade before the LBO arrival. The density of a downgrade at at time $s$ is given by $\pi^{r^{\prime}}\left(m_{0}, 0, s\right)$, upon which the security pays $f^{P}\left(\underline{V}_{P, s}\right)$. The probability of no LBO by $s$ is $e^{-\lambda s}$. Recalling that the LBO process is independent of the asset value and integrating the present discounted value for $s \in[0, T$ implies (48).

Let $F$ be the event that the firm's rating has always remained above speculative grade until the time of the LBO, but because of an insufficient firm value the LBO does not go through; subsequently the rating drops to speculative grade when $V$ hits $\underline{V}_{U, \tau_{P}}$ at $\tau_{P}$. The LBO is not consummated if the normalized value of the firm's assets is in $\left(\underline{v}_{P}, l\right)$; the transition density of this event is $p^{r}\left(q_{0}, y, 0, s\right)$. Subsequently the firm's normalized rating boundary is lowered to $\underline{v}_{U}$ and another appeal to the spatial homogeneity of Brownian Motion implies that the density of a rating downgrade after the LBO is $\pi^{r^{\prime}}\left(y+\underline{v}_{U}-\underline{v}_{L}, s, t\right.$. Now using the density of LBO arrival and integrating provides the expression for (49).

Let $G$ be the event that the firm's rating turns from investment to speculative grade at the time of LBO. This happens if the normalized if the firms value is in $\left[l, \underline{v}_{L}\right]$; the lower bound ensures that the LBO is consummated, and the upper that the firm's rating immediately turns to speculative grade - leading to an immediate payoff of the security. The actual value of the firm's assets is $e^{y} l P\left(r_{t}, T\right)$. Now performing the integration as for the other events yields (50). The last possibility is that the LBO is consummated 
Table 1: Average Cumulative Default Rates at Various Horizons (Percent)

\begin{tabular}{|l|r|r|r|r|r|}
\hline & \multicolumn{5}{|c|}{ Years After Issuance of Bond } \\
\cline { 2 - 6 } Initial Bond Rating & \multicolumn{1}{|c|}{1} & \multicolumn{1}{|c|}{5} & \multicolumn{1}{c|}{10} \\
\hline Investment-Grade & $\mathbf{. 0}$ & $\mathbf{. 2}$ & $\mathbf{. 8}$ & $\mathbf{2 . 4}$ & $\mathbf{6 . 6}$ \\
Aaa & .0 & .0 & .13 & .7 & 2.0 \\
Aa & .0 & .0 & .4 & 1.1 & 2.7 \\
A & .0 & .1 & .6 & 1.8 & 5.0 \\
Baa & .1 & .4 & 1.7 & 4.6 & 11.7 \\
Speculative-Grade & $\mathbf{3 . 9}$ & $\mathbf{7 . 8}$ & $\mathbf{1 5 . 4}$ & $\mathbf{2 6 . 1}$ & $\mathbf{4 1 . 3}$ \\
Ba & 1.4 & 3.7 & 11.6 & 20.9 & 37.8 \\
B & 7.3 & 13.9 & 29.5 & 44.3 & 52.9 \\
\hline
\end{tabular}

Source: Moody's (1997).

but the firm's rating remaines investment grade; this happens if the firm's normalized value is above $\underline{v}_{L}$. Subsequently, the firm's rating turns speculative grade after the firms value hits the upper rating boundary. Since this raises the rating boundary another appeal to spatial homogeneity implies that the subsequent density of the rating downgrade is $\pi^{r^{c}}\left(y-\left(\underline{v}_{U}-\underline{v}_{P}\right), 0, s, t\right)$. Again performing an integration over $t \in[0, T]$ yields (51). 
Table 2: Market Value of Assets, Credit Rating and the Value of Options

\begin{tabular}{ccccccc}
\hline Assets & $\pi_{20}$ & Rating & $I V^{o}$ & $S V^{o}$ & $I V$ & $S V$ \\
\hline 25 & .23 & Baa2 & .006 & .082 & .193 & 2.62 \\
60 & .11 & Baa1 & .004 & .066 & .098 & 1.43 \\
120 & .05 & $\mathrm{~A}$ & .002 & .038 & .048 & .77 \\
190 & .028 & Aa & .001 & .023 & .028 & .48 \\
240 & .020 & Aaa & .001 & .017 & .021 & .37 \\
\hline
\end{tabular}

The market value of the firm's assets are in the first column. $\pi_{20}$ is the 20-year probability of default starting with the asset value as shown, calculated using Lemma 3 . This default rate is usually associated with a Moody's rating shown in the following column. $I V^{o}$ and $S V^{o}$ give the intrinsic and strategic value of Ordinary Poison Puts. $I V$ and $S V$ give the intrinsic and strategic value of Super Poison Puts. The values of these securities are calculated using Results 3 and 4 . The parameters for the problem are $\rho=0, \sigma_{V}=.3$, $\lambda=.03, B=5.1, D^{N}=4.3$, and $D=.55 ;(6)$ and $(7)$ imply that $\nu=18.32$, and 44.76 .

Table 3: Correlation Between Asset Value and Short-Term Interest Rate and the Value of Options

\begin{tabular}{rrrrrrrrr}
\hline$\rho$ & \multicolumn{1}{c}{$\pi_{20}$} & $\underline{v}_{U}$ & $\underline{v}_{P}$ & $\underline{v}_{L}$ & $I V^{o}$ & $S V^{o}$ & $I V$ & $S V$ \\
\hline-.3 & .110 & 37.7 & 41.6 & 94.2 & .002 & .030 & .089 & 1.22 \\
-.2 & .122 & 39.7 & 43.9 & 99.3 & .003 & .043 & .106 & 1.39 \\
-.1 & .133 & 41.9 & 46.3 & 104.9 & .004 & .050 & .119 & 1.52 \\
.0 & .145 & 45.2 & 48.9 & 112.5 & .005 & .075 & .122 & 1.73 \\
.1 & .157 & 51.8 & 46.5 & 116.1 & .006 & .086 & .136 & 1.89 \\
.2 & .168 & 55.1 & 48.8 & 122.2 & .007 & .102 & .144 & 2.06 \\
\hline
\end{tabular}

\footnotetext{
The market value of assets in the example is $\$ 45 \mathrm{~b} . \pi_{20}$ is the 20 -year probability of default starting with the asset value as shown. The options payoff when the ratings decline to $\mathrm{Ba}$ on Moody's rating scale, which usually corresponds to a 20-year probability of default of $37.8 \%$. For each different $\rho$, the $\underline{v}_{K}$, for $K=P, L, U$ are calculated to imply this probability of default when the asset value in situation $K$ hits $\underline{v}_{K}$. $I V^{o}$ and $S V^{o}$ give the intrinsic and strategic value of Ordinary Poison Puts. $I V$ and $S V$ give the intrinsic and strategic value of Super Poison Puts.The values of these securities are calculated using Results 3 and 4. The common parameters for each case are, $\sigma_{V}=.3, \lambda=.03, B=5.1, D^{N}=4.3$, and $D=.55$. (6) and (7) imply that $\nu=18.32$, and 44.76.
} 
Figure 1: Acquisition Activity and Poison Put Issuance

Number of Completed Mergers

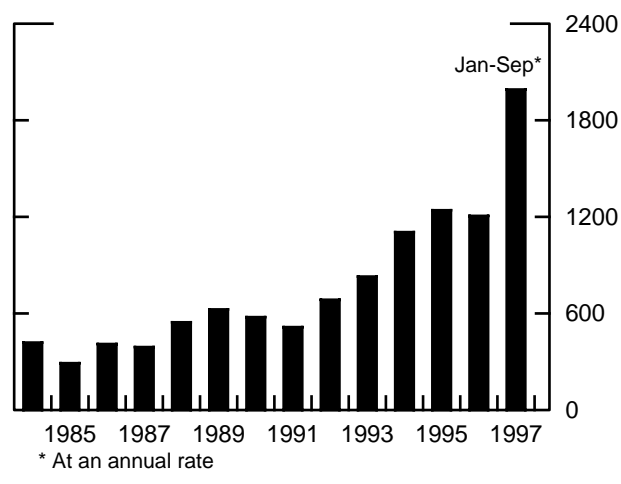

Number of Completed LBO and Investor Group Aquistions

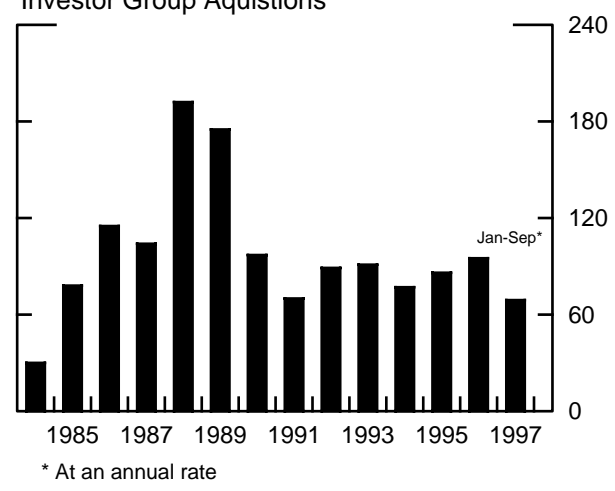

New Commitments to Non-Venture Private Equity Partnerships

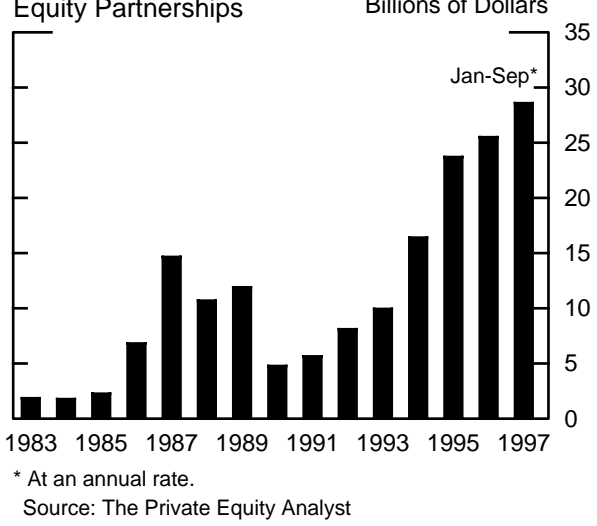

Volume of Merger Activity

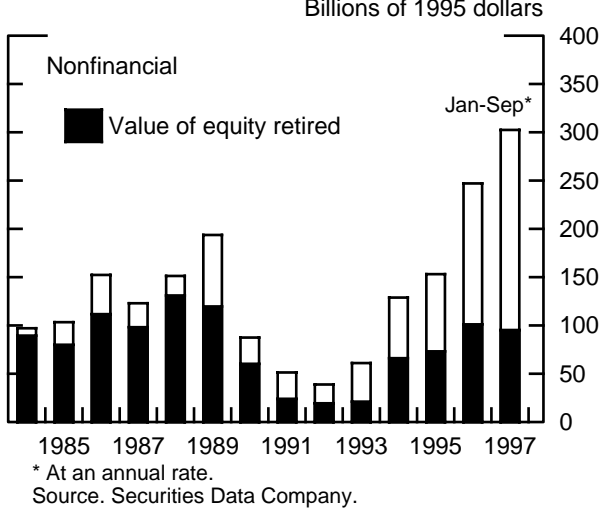

Completed Aquisitions by LBO Firms and Investor Groups ${ }^{1}$ Billons of Dollars

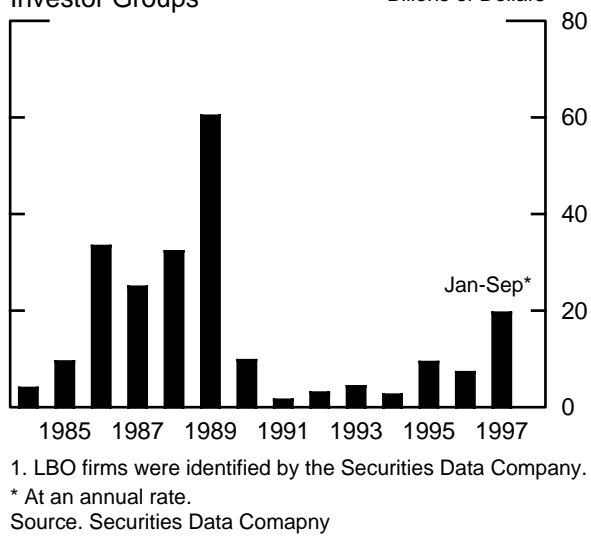

Public Issuance of Poison Put Bonds

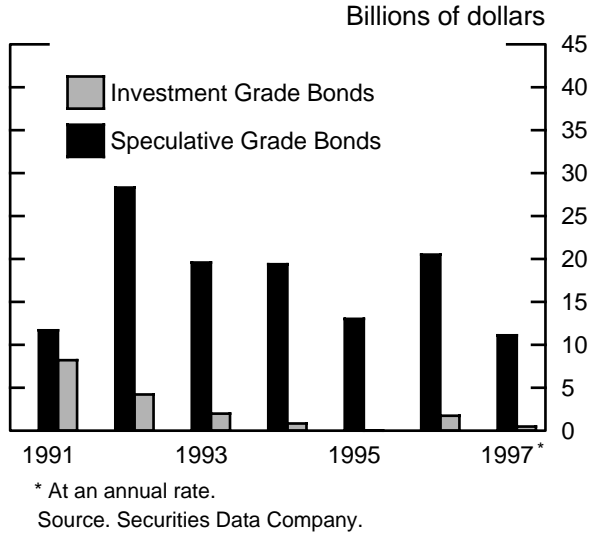

The merger series in the top panels represent the majority ( $>50 \%$ ) acquisition of public and private U.S. nonfinancial companies. The dark portion in the top right panel represents the equity of the target company retired as a result of the acquisition; the remainder of the deal value was paid in the stock of the acquirer. The number and the deal value of nonfinancial targets that were acquired by either LBO firms or private investor groups are shown in the middle panels. Funds raised by non-venture private equity investors — which include specialist LBO firms - are shown in the bottom left panel. The face value of Poison Put bonds issued in the 1990s is shown in the bottom right panel. 
Figure 2: Kmart's Market Statistics
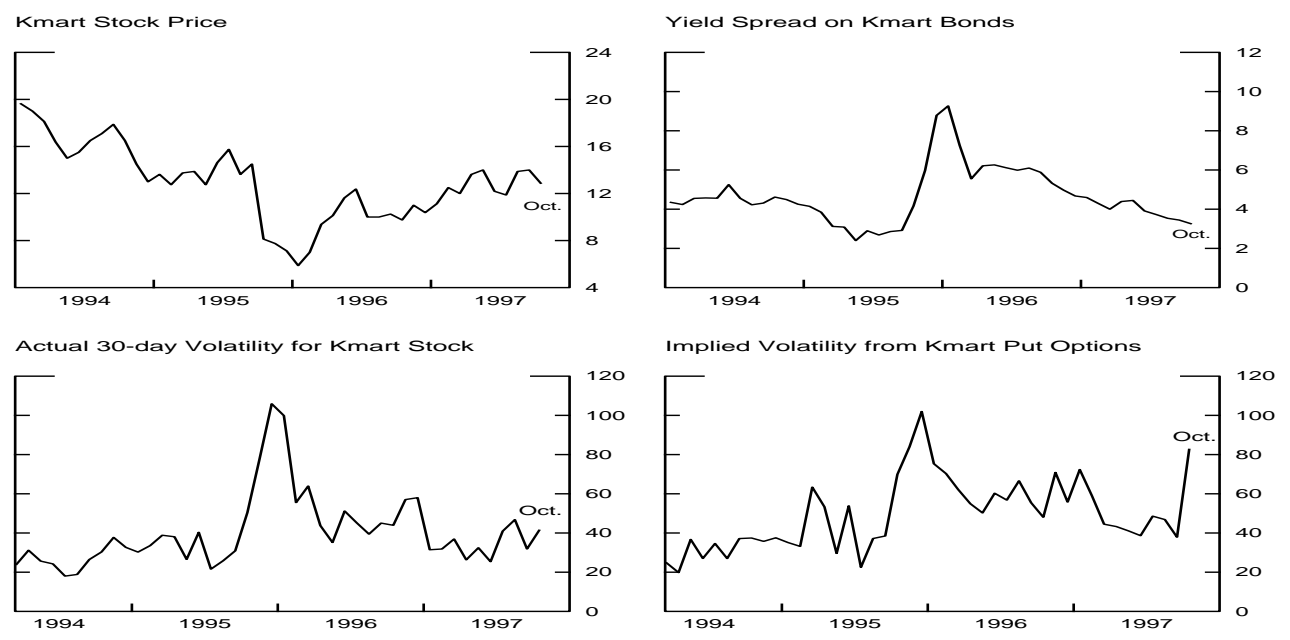

Source: Bloomberg Financial Markets. The series above are monthly averages. The yield spread in the top right panel is the yield on Kmart's $8 \frac{1}{4}$ coupon bonds minus the average monthly Federal Funds rate. The volatility estimate in the bottom left panel is a 10-day moving average of squared returns. Implied volatility, shown in the bottom right panel, is the average Black-Scholes implied volatilities on short-term at-the-money options. Each of the series shown indicate increased market uncertainty around December 1995.

Figure 3: The Effect of an LBO on the Probability of Default

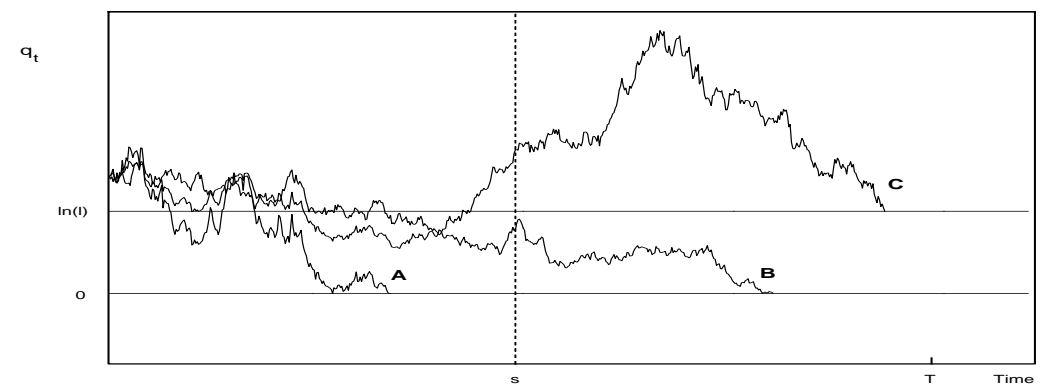

The firm defaults on all its liabilities when the value of its assets, $V_{t}$, hits the stochastic boundary $\nu_{t}$, given in (6) or equivalently when $q_{t} \equiv \ln \left(\frac{V_{t}}{\nu_{t}}\right)$ hits zero. If the firm is purchased in a LBO transaction, the boundary is increased to $\nu_{t}^{L}$, given in (7). The time of the LBO is stochastic; in the figure it is assumed that the LBO offer arrives at time $s$. For every $s \in[0, T]$, there are three types of asset paths that lead to default: $q_{t}$ hits 0 prior to the LBO in paths of Type A; paths of Type B have $\nu_{s} \leq V_{s} \leq \nu_{s}^{L}$, or equivalently $0 \leq q_{s} \leq \ln (l)$, where $l=\frac{\alpha_{B} B+\beta \alpha_{D} D}{\alpha_{B} B+\alpha_{D} D}$, therefore, the LBO is not consummated, the default boundary is not increased, and the firm defaults when $q_{t}$ hits $0, T \geq t>s$; paths of Type C, lead to a successful LBO transaction at $s$ and a subsequent default when $q_{t}$ hits $\ln (l)$ prior to $T$. 
Figure 4: Anatomy of A Put Bond Induced Financial Crisis

Value of Claims In An Immediate Reorganization

\begin{tabular}{|cl}
\hline$\underline{\text { Liabilities }}$ & \\
Non-Putable Senior Debt: & $B_{\tau_{P} F}=\min \left\{(1-\Phi) V_{\tau_{P}}, B f_{B} P\left(r_{\tau_{P}}, \tau_{P}, T\right)\right\}$ \\
Non-Putable Junior Debt: & $D_{\tau_{P} F}^{N}=\frac{D^{N}}{D+D^{N}} \min \left\{(1-\Phi) V_{\tau_{P}}-B_{\tau_{P} F}, D f_{D} P\left(r_{\tau_{P}}, \tau_{P}, T\right)\right\}$ \\
Putable Debt: & $D_{\tau_{P} F}=\frac{D}{D+D^{N}} \min \left\{(1-\Phi) V_{\tau_{P}}-B_{\tau_{P} F}, D f_{D} P\left(r_{\tau_{P}}, \tau_{P}, T\right)\right\}$ \\
Shareholder Equity: & $E_{\tau_{P} F}=V_{\tau_{P}}-B_{\tau_{P} F}-D_{\tau_{P} F}$ \\
$(1-\Phi) V_{\tau_{P}}$ & $(1-\Phi) V_{\tau_{P}}$ \\
&
\end{tabular}

Balance Sheet at Time of Crisis (Market-Value)

\begin{tabular}{|lll|}
\hline \multicolumn{1}{|c|}{ Liabilities } & \\
& Non-Putable Senior Debt: & $B P_{B}$ \\
& Non-Putable Junior Debt: & $D^{N} P_{D}$ \\
& Putable Debt: & $D P_{D}$ \\
& Shareholder Equity: & $E$ \\
& & \\
$V_{\tau_{P}}$ & $\downarrow$ & \\
\hline
\end{tabular}

Balance Sheet (Market-Value) After Succesful Options Transaction

\begin{tabular}{|c|c|c|}
\hline$\underline{\text { Assets }}$ & $\underline{\text { Liabilities }}$ & \\
\hline & Senior Debt: & $B P_{B}$ \\
\hline & Junior Debt: & $\left(D_{C}+D^{N}\right) P_{D}$ \\
\hline & Bail-Out Loan: & $D_{P}+X_{C}$ \\
\hline & Shareholder Equity: & $E$ \\
\hline$V_{\tau_{P}}$ & & $V_{\tau_{P}}$ \\
\hline
\end{tabular}

Recoveries in Insolvent State

\begin{tabular}{|cc|}
\hline$\underline{\text { Assets }} \quad \underline{\text { Liabilities }}$ & \\
Senior Debt: & $B_{T F}=\alpha_{B} B f_{B}$ \\
Junior Debt: & $D_{T F}=\alpha_{D}\left(D_{C}+D^{N}\right) f_{D}$ \\
Bail-Out Loan: & $L_{T F}=0$ \\
Shareholder Equity: & $E_{T F}=\alpha_{E}(1-\Phi) V_{\tau_{D}}$ \\
$(1-\Phi) V_{\tau_{D}}$ & $(1-\Phi) V_{\tau_{D}}$ \\
\end{tabular}

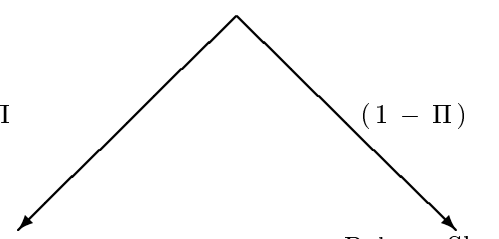

Balance Sheet (Market-Value) in Solvent State

\begin{tabular}{|c|c|c|}
\hline Assets & \multicolumn{2}{|c|}{$\underline{\underline{\text { Liabilities }}}$} \\
\hline & Senior Debt: & $B_{T S}=B f_{B}$ \\
\hline & Junior Debt: & $T S=\left(D_{C}+D^{N}\right) f_{D}$ \\
\hline & Bail-Out Loan: & $L_{T S}=\left(D_{P}+X_{C}\right) \cdot f_{L}$ \\
\hline & Shareholder Equity: & $E_{T S}=V_{T}-B_{T S}-D_{T S}-L_{T S}$ \\
\hline$V_{T}$ & & $V_{T}$ \\
\hline
\end{tabular}


Figure 5: Proportion of Coalitions That Avoid A Reorganization and Strategic Value Per Dollar of Putable Bond

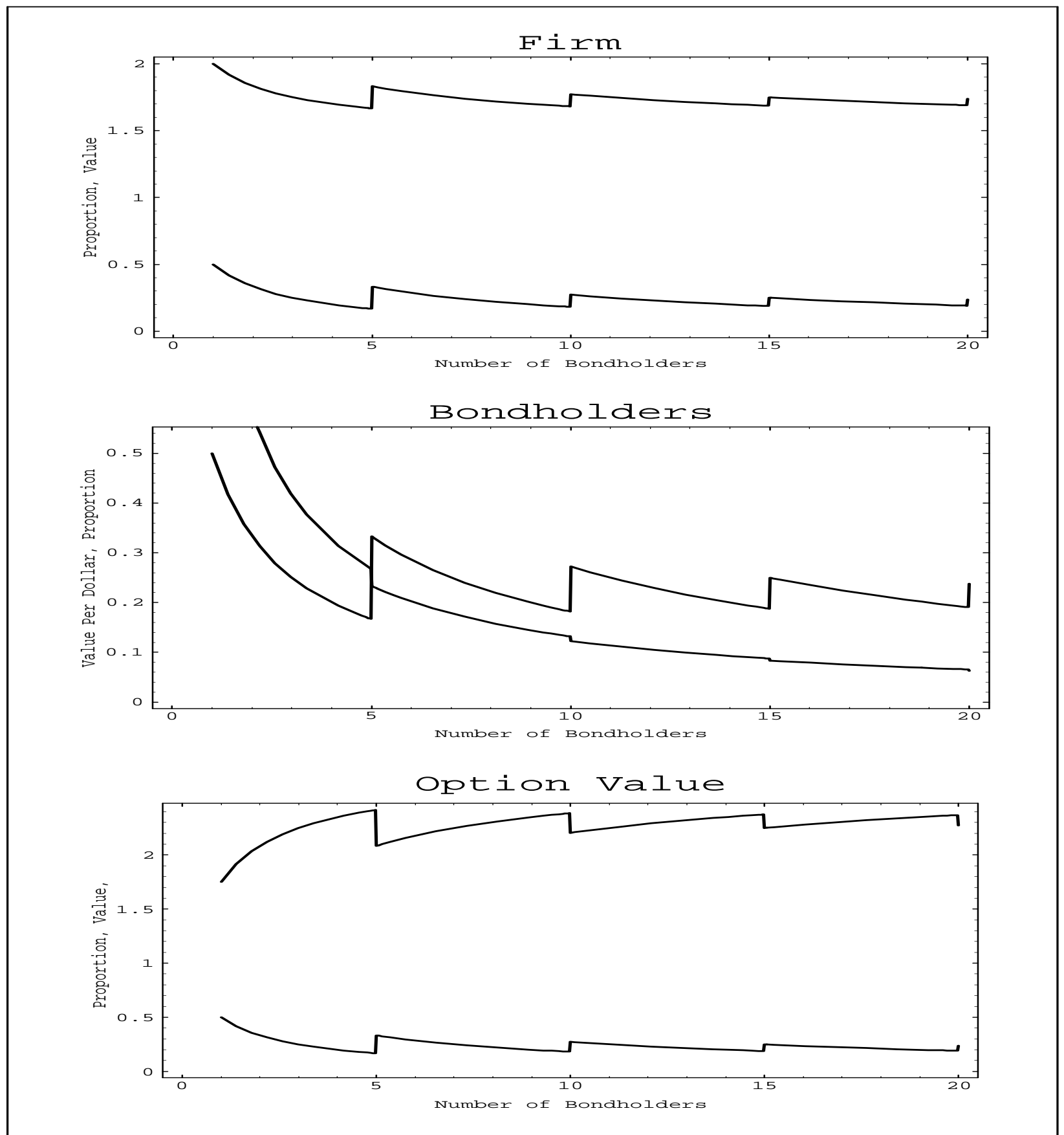

The strategic value of the players are calculated as shown in Lemma 2. The strategic value of the option is defined in (33). The following parameters describe the problem: $\bar{v}=3, D=.5, f_{D}=2.5, P\left(r_{\tau_{P}}, T\right)=.4, D_{\tau_{P} F}=.5$, $T=.1, E_{\tau_{P} F}=2$, and $\pi_{T}=.25$. The proportion shown on the axes equals $\frac{M^{c}}{N+1}$; it represents the proportion of all coalitions (including the firm) in which the firm reaches a settlement and avoids bankruptcy. 
Figure 6: One Large and One Small Bondholder

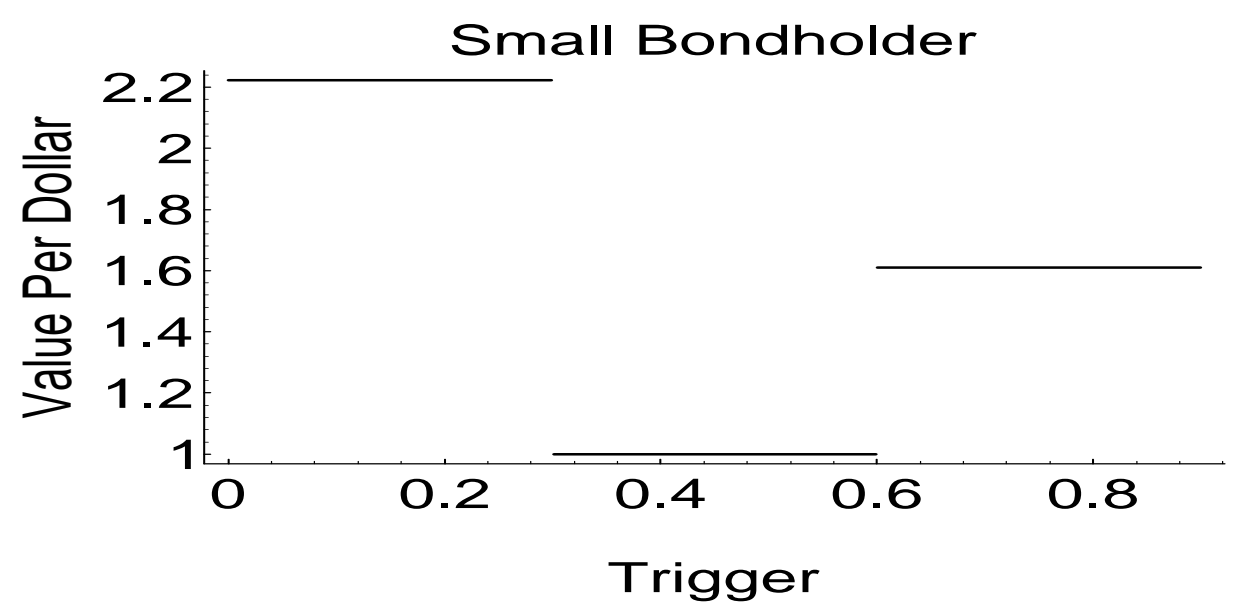

Large Bondholder

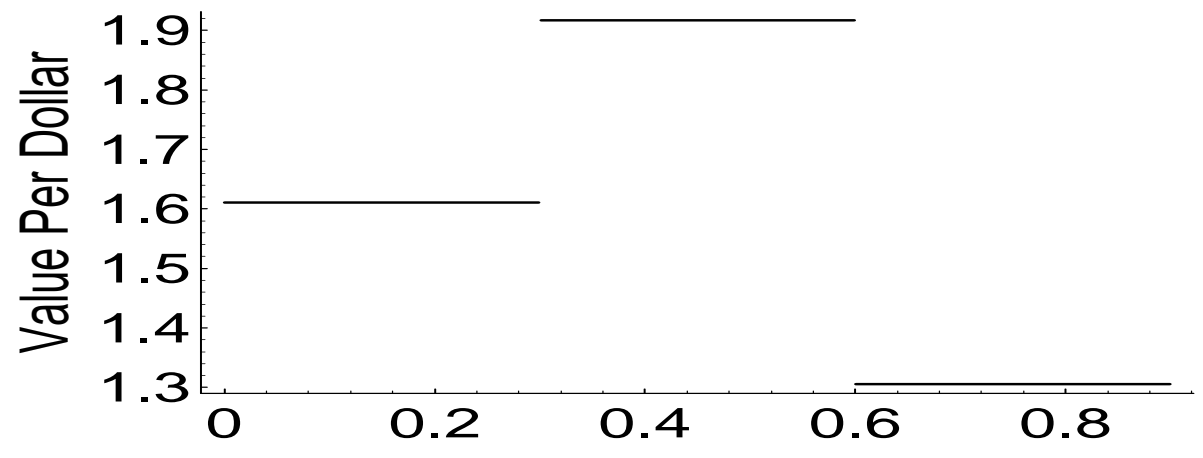

Trigger

Firm

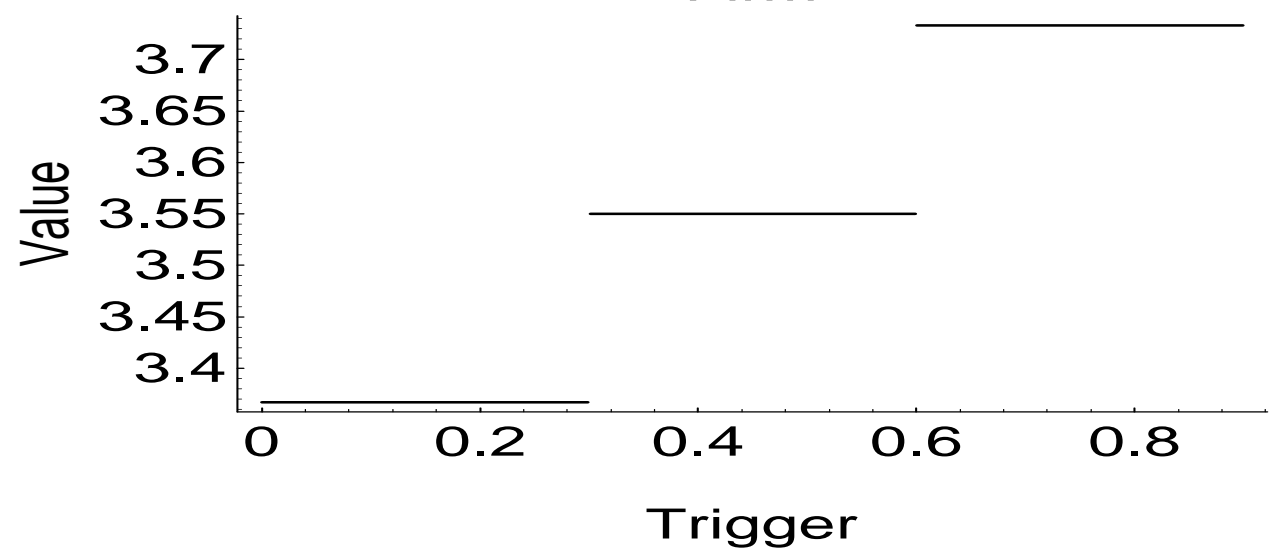

The strategic value of the players are calculated as shown in Lemma 8. The strategic value of the option is defined in (33). The following parameters describe the problem: $\bar{v}=5, D=.3, D_{1}=.6, f_{D}=2.5, P\left(r_{\tau_{P}}, T\right)=.4$, $E_{\tau_{P} F}=3$, and $\pi_{T}=.25$. The figures show the values of the players as the trigger level is increased from 0 to $D+D^{1}$. 
Figure 7: One Large and Several Small Bondholder

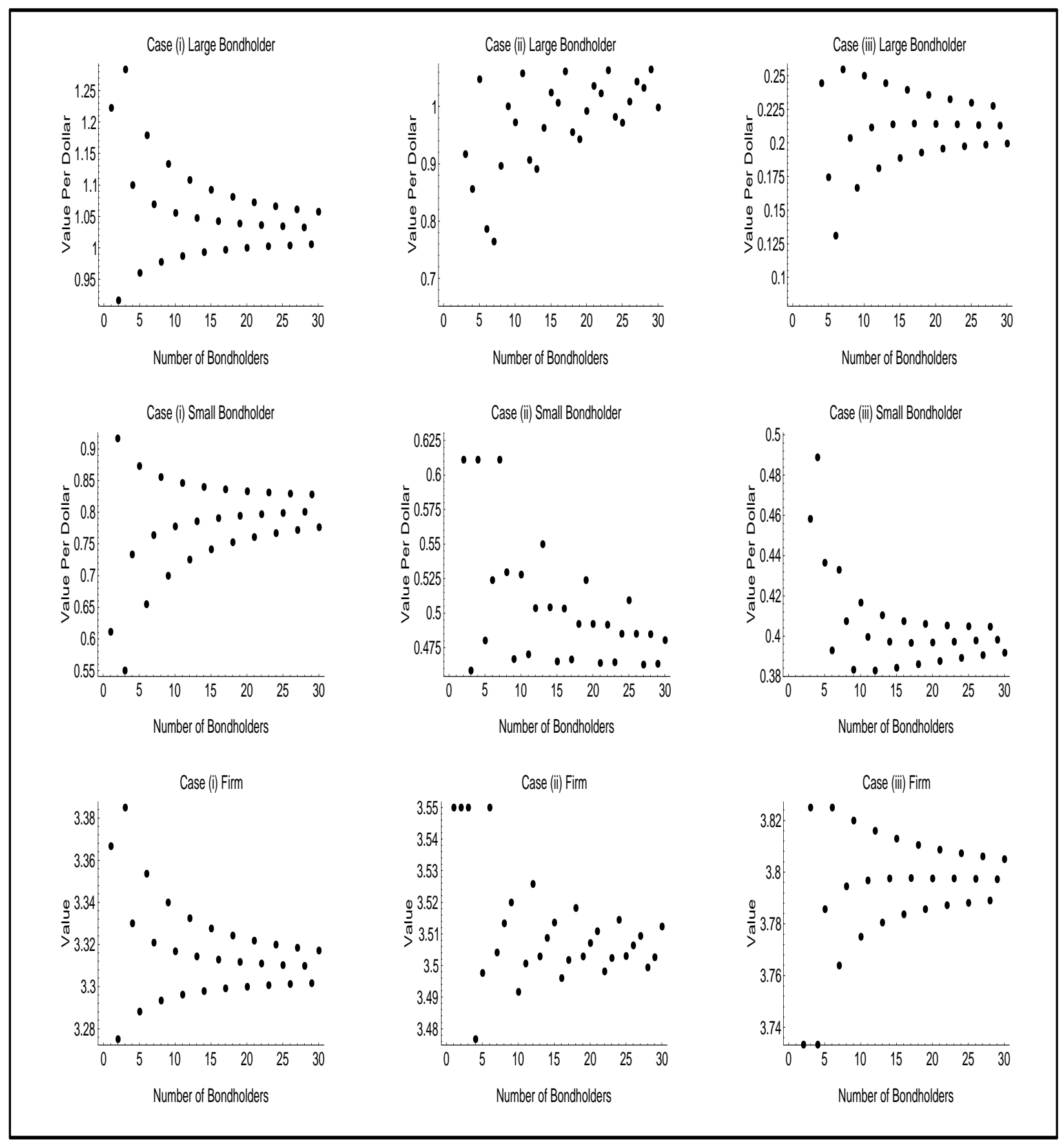

The strategic value of the players are calculated as shown in Lemma 8. The strategic value of the option is defined in (33). The following parameters describe the problem: $\bar{v}=5, D=.6, D_{1}=.3, f_{D}=2.5, P\left(r_{\tau_{P}}, T\right)=.4$, $E_{\tau_{P} F}=3$, and $\pi_{T}=.25$. The figures show the values of the players as the trigger level is increased from 0 to $D+D^{1}$. The number of small bondholders is allowed to vary between 1 and 30 . Three separate cases are considered: In Case (i) $T=.2$, in Case (ii) $T=.4$, and in Case (iii) $T=.7$. 
Figure 8: Payoffs of A Super Poison Put Bond

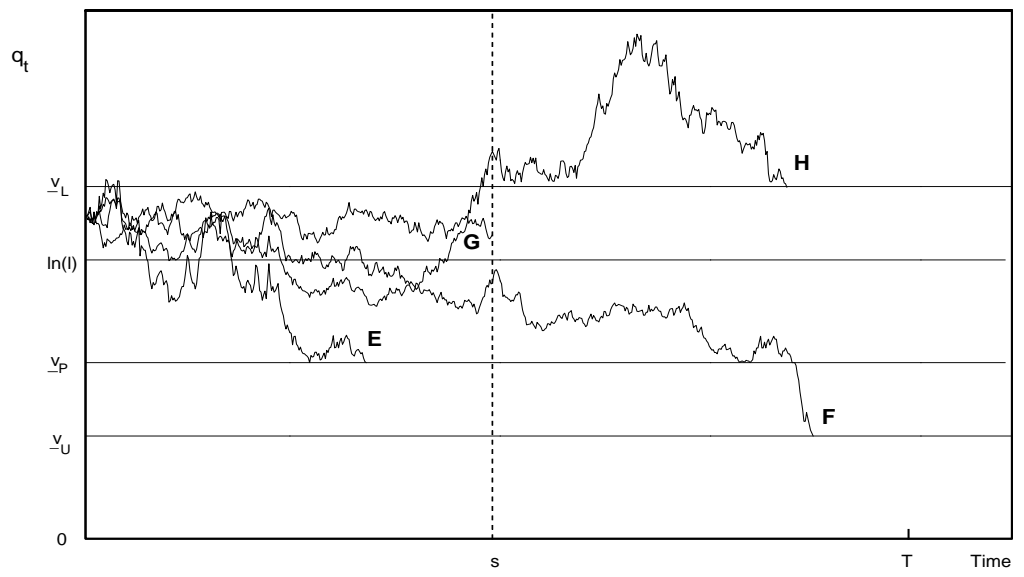

The firm's rating hits speculative grade in the situation $K$ when the value of its assets, $V_{t}$, hits the stochastic rating boundary $\underline{V}_{K t}$, for $K P L U-$ or equivalently $q_{t}=\ln \left(\frac{V_{t}}{\nu P\left(r_{t}, T\right)}\right)$ hits $\underline{v}_{K}$. When the firm's value hits this lower bound the probability of defaulting at different time horizons matches the default rate of Ba-rated firms by Moody's. The value of a security that pays the value $f\left(V_{\tau_{P}}\right)$ can be written as the sum of its values in four mutually exclusive events, i.e. $P_{0}(f)=P_{0}^{E}(f)+P_{0}^{F}(f)+P_{0}^{G}(f)+P_{0}^{H}(f)$. In event $E$, the firm's rating hits speculative grade before the LBO arrival. In event $F$, the firm's rating remains above speculative grade until the time of the LBO, but because of an insufficient firm value, the LBO does not go through; subsequently, the rating drops to speculative grade when $\left\{q_{t}\right\}$ hits $\underline{v}_{U}$. In event $G$, the firm's rating turns from investment to speculative grade at the time of LBO. This happens if the normalized firm value is in $\left[\ln (l), \underline{v}_{L}\right]$; the lower bound ensures that the LBO is consummated, and the upper that the firm's rating immediately turns to speculative grade - leading to an immediate payoff of the security. Under event $H$, the firm's rating remains investment grade until the LBO arrival, the LBO is consummated but the firm's rating remains investment grade; this happens if the firm's normalized value is above $\underline{v}_{L}$. Subsequently, the firm's rating turns speculative grade after $\left\{q_{t}\right\}$ hits $\underline{v}_{L}$. 


\section{References}

Aivazian, Varouj A. and Jeffrey L. Callen, "Reorganization in Bankruptcy and the Issue of Strategic Risk," Journal of Banking and Finance, 1983, 7, 119-133.

Anderson, Ronald W. and Suresh Sundaresan, "Design and Valuation of Debt Contracts," The Review of Financial Studies, 1996, 9 (1), 37-68.

Bergman, Yacov Z. and Jeffrey L. Callen, "Opportunistic Underinvestment in Debt Renegotiation and Capital Structure," Journal of Financial Economics, 1991, 29, 137-171.

Black, Fischer and John C. Cox, "Valuing Corporate Securities: Some Effects of Bond Indenture Provisions," The Journal of Finance, 1976, 31, 351-367.

Brennan, Michael J. and Eduardo S. Schwartz, "Optimal Financial Policy and Firm Valuation," The Journal of Finance, 1984, 39 (3), 593-607.

, Jerome Detemple, and Avner Kalay, "Bond Covenants and the Valuation of Risky Debt: A New Approach," First Boston Working Paper Series FB 90-01, Graduate School of Business, Columbia University November 1989.

Briys, Eric and Francois de Varenne, "Valuing Risky Fixed Rate Debt: An Extension," Journal of Financial and Quantative Analysis, 1997, 33 (2), 239-248.

Carey, Mark, Stephen Prowse, John Rea, and Gregory Udell, "The Economics of Private Placements: A New Look," Financial Markets, Institutions \& Instruments 3, New York University, Salomon Center 1993.

Chan, K. C., G. Andrew Karolyi, Francis A. Longstaff, and Anthony B. Sanders, "An Empirical Comparison of Alternative Models of the Short-Term Interest Rate," The Journal of Finance, 1992, 47 (3), 1209-1227.

Cook, Douglas O. and John C. Easterwood, "Poison Put Bonds: An Analysis of Their Economic Role," The Journal of Finance, 1994, 49 (5), 1905-1920.

Crabbe, Leland, "Event Risk: An Analysis of Losses to Bondholders and "Super Poison Put" Bond Covenants," The Journal of Finance, 1991, 46, 689-706.

Degroot, Morris H., Probability and Statistics, Addison-Wesley, Reading, Massachusetts, 1985.

Duffie, Darell and Kenneth J. Singleton, "Modeling the Term Structure of Defaultable Bonds," March 1995.

Duffie, Darrell, Dynamic Asset Pricing Theory, Princeton University Press, Princeton, New Jersey, 1992. 
Dunn, Kenneth B. and Chester S. Spatt, "A Strategic Analysis of Sinking Fund Bonds," Journal of Financial Economics, 1984, 13 (3), 399-423.

Fenn, George W., Nellie Liang, and Stephen Prowse, "The Private Equity Market: An Overview," Financial Markets, Institutions \& Instruments 4, New York University, Salomon Center 1997.

Franks, Julian and Walter Torous, "An Empirical Investigation of Firms in Reorganization," The Journal of Finance, 1989, 44, 747-779.

Harrison, J. Michael, Brownian Motion and Stochastic Flow Systems, John Wiley and Sons, New York, 1985.

Harsanyi, John C., "The Shapley Value and the Risk Dominance Solutions of Two Bargaining Models for Characteristic-Function Games," in Robert J. Aumannn et al., ed., Essays in Game Theory and Mathematical Economics, Mannheim: Bibliographisches Institut Mannheim, 1981.

Hart, Sergiu and Andreu Mas-Colell, "Bargaining and Value," Econometrica, 1996, 64 (2), 357-380.

Jones, E. Phillip, Scott P. Mason, and Eric Rosenfeld, "Contingent Claims Analysis of Corporate Capital Structures: an Empirical Investigation," The Journal of Finance, 1994, 39 (3), 611-625.

Leland, Hayne E., "Corporate Debt Value, Bond Covenants, and Optimal Capital Structure," The Journal of Finance, 1994, 49, 1213-1252.

and Klaus B. Toft, "Optimal Capital Structure, Endogenous Bankruptcy, and the Term Structure of Credit Spreads," The Journal of Finance, 1996, 51 (3), 987-1019.

Longstaff, Francis A. and Eduardo S. Schwartz, "A Simple Approach to Valuing Risky Fixed and Floating Rate Debt," The Journal of Finance, 1996, 50, 789-819.

Madan, Dilip B. and Haluk Unal, "Pricing the Risks of Default," 1994.

Mella-Berral, Pierre and William Perraudin, "Strategic Debt Service," The Journal of Finance, 1997, $52(2), 531-556$.

Merton, Robert C., "On the Pricing of Corporate Debt: The Risk Structure of Interest Rates," The Journal of Finance, 1974, 29, 449-470.

Moody's, Investor Service, "Historical Default Rates of Corporate Bond Issuers," Global Credit Research 1997.

Nash, Robert, Jeffry M. Netter, and Annette B. Poulsen, "Determinants of Contractual Relations Between Shareholders and Bondholders - Investment Opportunities and Restrictive Covenants," March 1997. 
Ostroy, Joseph M., "A Reformulation of the Marginal Productivity Theory of Distribution," Econometrica, 1984, 52, 599-630.

Rubinstein, Ariel, "Perfect Equilibrium in a Bargaining Model," Econometrica, 1982, 50, 97-109.

Smith, Clifford W. and Jerold B. Warner, "On Financial Contracting," Journal of Financial Economics, 1979, 7, 117-161.

Sutton, John, "Non-Cooperative Bargaining Theory: An Introduction," Review of Economic Studies, 1986, pp. 709-724.

Vasicek, Oldrich, "An Equilibrium Characterization of the Term Structure," Journal of Financial Economics, 1977, 5, 177-188.

Warga, Arthur and Ivo Welch, "Bondholder Losses in Leveraged Buyouts," The Review of Financial Studies, 1993, 6 (4), 959-982.

Weberman, Ben, "One Man's Poison," Forbes magazine, 1988, (22), 117.

Weiss, Lawerence A., "Bankruptcy Resolution. Direct Costs and Violation of Priority of Claims," Journal of Financial Economics, 1990, 27 (3), 285-314.

Winter, Eyal, "The Demand Commitment Bargaining and Snowballing Cooperation," Economic Theory, 1994, 4, 255-273.

Wrinkler, Matthew, "Harris, Williams Cos. Are First to Offer Super 'Poison Puts'," 16th November, The Wall Street Journal 1988.

Zhou, Chungsheng, "A Jump-Diffusion Approach to Modeling Credit Risk and Valuing Defaultable Securities," Finance and Economics Discussion Series, 1997-15, Board of Governors of the Federal Reserve System, June 1997. 